\title{
Systematic Review on Treatments for Acute Pain: Surveillance Report 1
}

\author{
Literature Update Period: August 2020 through October 2021
}

\section{Background and Purpose}

This is the first update for the 2020 report Treatments for Acute Pain: A Systematic Review (https:/leffectivehealthcare.ahrq.gov/products/treatments-acute-pain/research), ${ }^{1}$ covering the period August 2020 through October 2021. The 2020 report addressed benefits and harms of opioid, nonopioid pharmacologic, and nonpharmacologic treatments for specific types of acute pain (low back pain, neck pain, other musculoskeletal pain, neuropathic pain, postoperative pain [excluding inpatient management of pain after major surgical procedures], dental pain, pain due to kidney stones, and pain due to sickle cell disease). Given the clinical and public health importance of this topic, it is important to identify new evidence that could impact practice or policy. The purpose of this update is to identify new evidence published since the 2020 report and to determine how the new evidence impacts its findings. Subsequent updates are planned for February 2022 (based on evidence published from November 2021 to January 2022) and May 2022 (based on evidence published from February to April 2022).

\section{Scope}

The scope and eligibility criteria established at the time of the original report ${ }^{1}$ were utilized for this surveillance report; no changes were made. The report addressed the following acute pain conditions:

- Acute back pain (including back pain with radiculopathy) (Key Question [KQ] 1)

- Acute neck pain (including neck pain with radiculopathy) (KQ 2)

- Musculoskeletal pain not otherwise included in KQ 1 or KQ 2 (including fractures) (KQ 3)

- Peripheral neuropathic pain (related to herpes zoster and trigeminal neuralgia) (KQ 4)

- Postoperative pain (excluding inpatient management of pain following major surgical procedures (KQ 5)

- Dental pain (KQ 6)

- Kidney stones (including inpatient management) (KQ 7)

- $\quad$ Sickle cell crisis (episodic pain) (KQ 8)

For each of these acute pain conditions, the report addressed the effectiveness and comparative effectiveness (benefits and harms) for the following comparisons:

- Opioid therapy versus nonopioid pharmacologic therapy (acetaminophen, non-steroidal anti-inflammatory drugs [NSAIDs], skeletal muscle relaxants, benzodiazepines, antidepressants, anticonvulsants, cannabis) or nonpharmacologic therapy (exercise, cognitive behavioral therapy, meditation, relaxation, music therapy, virtual reality, acupuncture, massage, manipulation/mobilization, physical modalities).

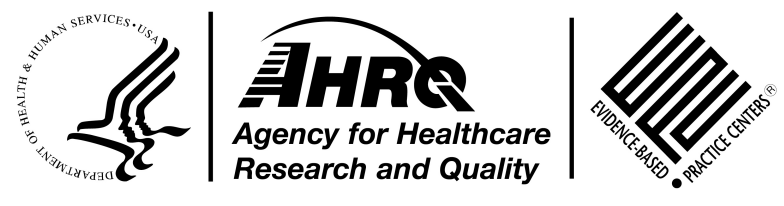


- Nonopioid pharmacologic therapy versus other nonopioid pharmacologic treatments or nonpharmacologic therapy.

- Nonpharmacologic therapy versus inactive treatments or usual care.

The report also addressed how benefits and harms varied according to demographic, clinical, and medication factors; effects of prescribing opioid therapy for acute pain conditions on shortand long-term opioid use; and factors associated with opioid prescribing for acute pain conditions. The full protocol for the original report, including detailed inclusion criteria using the PICOTS (populations, interventions, comparisons, outcomes, timing, settings) framework (https://www.ncbi.nlm.nih.gov/books/NBK566503/table/appb.tab1/?report=objectonly) and full KQs (https://www.ncbi.nlm.nih.gov/books/NBK566501/\#ch3.s2), is shown in the appendixes and is also available on the Agency for Healthcare Research and Quality website (https://effectivehealthcare.ahrq.gov/products/treatments-acute-pain/protocol) and on the PROSPERO systematic reviews registry (CRD42020165677).

\section{Methods}

Update searches were conducted to identify evidence published from August 2020 through October 2021. Search strategies from the original report were utilized ${ }^{1}$ and we searched the same databases as in the original report $\left(\right.$ Ovid $^{\circledR}$ MEDLINE ${ }^{\circledR}$, PsycINFO $^{\circledR}$, Embase $^{\circledR}$, the Cochrane Central Register of Controlled Trials, and the Cochrane Database of Systematic Reviews). In addition, to capture articles not yet indexed in MEDLINE, we supplemented the original search strategies with an optimized (text-word only) search ${ }^{2}$ in pre-MEDLINE to identify studies not yet indexed with Medical Subject Headings (MeSH). As in the original report, searches on electronic databases were for studies in English and supplemented by review of reference lists of relevant articles. Search strategies are available in Appendix A. Randomized controlled trials were included for all KQs. For opioid prescribing and long-term use, accuracy and effectiveness of risk prediction instruments, and factors influencing prescribing, controlled observational studies (cohort, case-control, and before-after studies) were also included.

For this update, one investigator screened all citations identified through searches for eligibility for full-text review. (KQs and inclusion criteria are available in Appendix B.) In addition, to increase efficiency of abstract review, we utilized the artificial intelligence function in Distiller SR (DistillerSR AI) in conjunction with a second investigator to assist in conducting dual review. DistillerSR AI utilizes Natural Language Processing to train itself and make inclusion predictions using manually reviewed references. For this update, DistillerSR AI was trained using 2,132 abstracts identified in the initial update search and manually reviewed by one investigator. Following training, DistillerSR AI assigned a certainty score for each citation, indicating how likely it was to qualify for inclusion (from 0.0 to 1.0 probability of inclusion). DistillerSR AI assigned a certainty score to all citations; the second investigator performed dual review on all studies assigned a DistillerSR AI certainty score of 0.40 or more. Any citation identified as potentially eligible by either reviewer underwent full-text review to determine final eligibility.

We utilized the same methods for data abstraction and quality assessment as the original report. We assessed the quality of individual controlled trials using the approach recommended in the chapter Assessing the Risk of Bias of Individual Studies When Comparing Medical Interventions in the Methods Guide for Effectiveness and Comparative Effectiveness Reviews, developed by the Agency for Healthcare Research and Quality, ${ }^{3}$ in conjunction with criteria and 
methods developed by the Cochrane Back Review Group. ${ }^{4}$ We excluded combination treatments except for an opioid plus NSAIDs or acetaminophen, as these combinations are commonly used in clinical practice and frequently evaluated in clinical trials. When possible, we stratified comparisons according to whether an opioid was administered alone or in combination with an NSAID or acetaminophen. We separately evaluated single dose trials and multidose trials (i.e., trials that evaluated a course of more than one dose of therapy).

The decision to update meta-analyses from the original report was based on the number and sample sizes of new studies eligible for meta-analysis (meta-analysis performed if new evidence was large relative to the studies in the original meta-analysis); consistency in findings between the new studies and the original meta-analysis (meta-analysis performed if findings from new evidence appear inconsistent and new studies were appropriate for pooling based on similarity in populations, interventions, and comparisons, in order to determine whether new studies impact conclusions); or whether new evidence could impact the strength of evidence (meta-analysis performed if the strength of evidence based on the original meta-analysis was low or insufficient and new evidence could increase the strength of evidence due to increased precision, high quality, or other factors). The strength of evidence was based on the totality of evidence (evidence in the original report plus new evidence) and determined using the methods described in the original report. We highlighted any changes in the strength of evidence assessments.

A list of included studies identified for this update is provided in Appendix $\mathrm{C}$ and a list of articles excluded at full text, along with reasons for exclusion, is available in Appendix D. Evidence tables providing data from included studies are available in Appendix E, and quality assessments for each study are shown in Appendix F.

\section{Results}

The update search yielded 2,602 citations, and identified 13 new eligible studies (all randomized controlled trials [RCTs]) (Figure 1). One trial was conducted in patients with acute low back pain (acupuncture vs. usual care) ${ }^{5}$ two trials in patients with other musculoskeletal pain ( 1 trial evaluated opioid vs. acetaminophen ${ }^{6}$ and 1 trial evaluated topical ibuprofen vs. topical capsaicin ${ }^{7}$ ); seven trials in patients with postoperative pain ( 1 trial evaluated an opioid vs. NSAID,${ }^{8} 1$ trial an opioid vs. acetaminophen, ${ }^{9} 1$ trial an opioid vs. mixed agent, ${ }^{10} 3$ trials cold therapy vs. usual care, ${ }^{11-13}$ and 1 trial music therapy vs. no music therapy ${ }^{14}$ ); and three trials in patients with dental pain ( 2 trials evaluated an opioid vs. NSAID, ${ }^{15,16} 2$ trials evaluated an opioid vs. acetaminophen, ${ }^{16,17}$ and 1 trial an NSAID vs. acetaminophen ${ }^{16}$ ). For acute musculoskeletal pain, the new trials evaluated comparisons for which there was no evidence in the original report; otherwise, the new evidence addressed comparisons with at least some prior evidence. No new eligible studies were identified for acute neck pain, peripheral neuropathic pain, kidney stone pain, or sickle cell pain; effects of opioid use versus non-use for specific pain conditions and likelihood of short- or long-term use; or factors associated with opioid prescribing for specific acute pain conditions. Two trials were rated good quality, ${ }^{6,15} 10$ trials were rated fair quality, ${ }^{5,8-}$ $14,16,17$ and 1 trial was rated poor quality (Appendix F). ${ }^{7}$ Methodological limitations in the fairquality trials included failure to report randomization or allocation concealment methods, openlabel design, or high attrition. The poor-quality trial ${ }^{7}$ had high attrition and did not conduct intention-to-treat analysis. 
Figure 1. Literature flow diagram

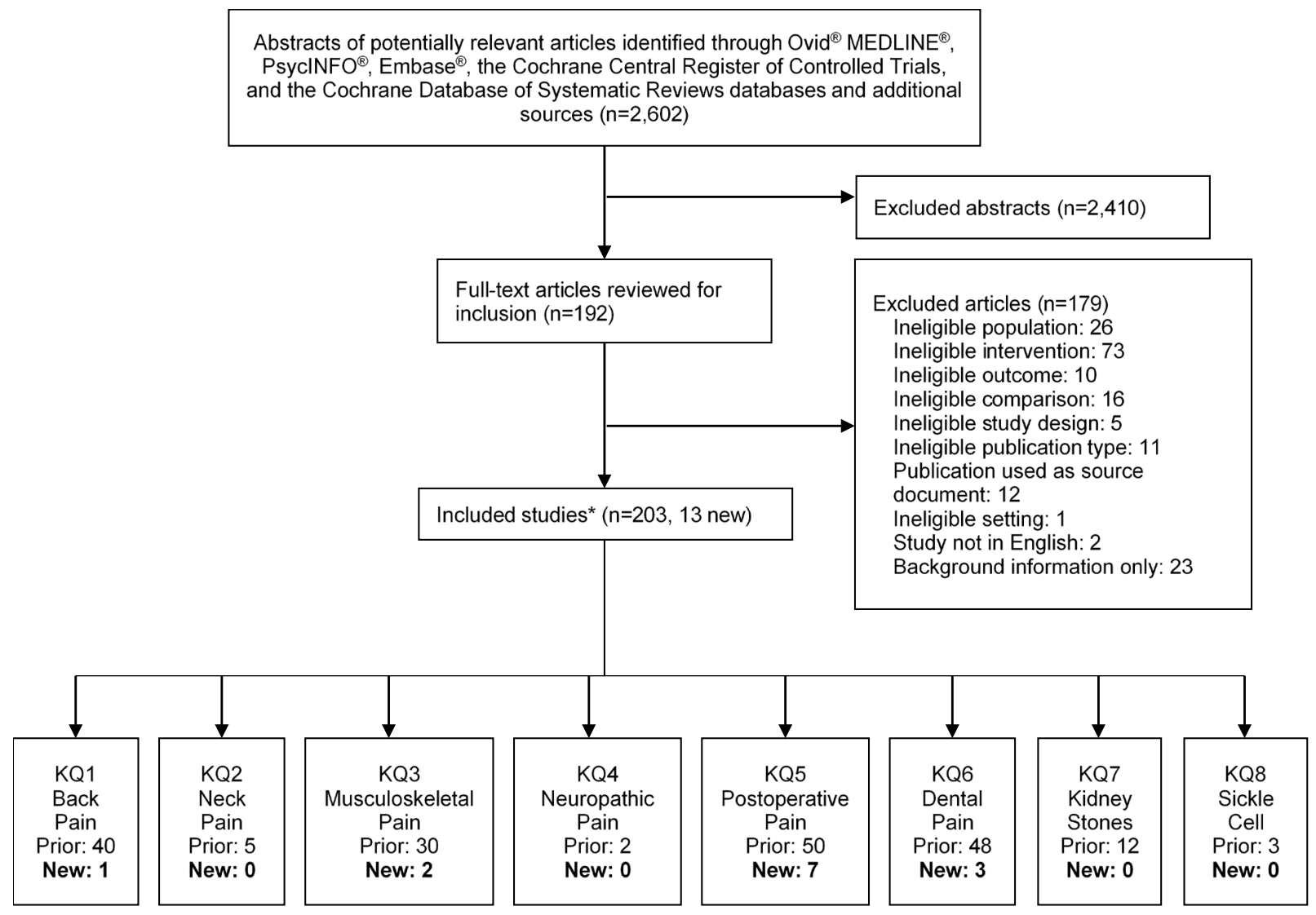

Abbreviations: KQ = Key Question

*Additional sources include prior reports, reference lists of relevant articles, systematic reviews, etc.

\section{Summary of Findings}

- Thirteen new RCTs were identified for this update. Two of the new trials (noted below) evaluated comparisons not previously evaluated for acute musculoskeletal pain; otherwise, the trials evaluated comparisons for specific acute pain conditions with at least some prior evidence.

\section{KQ1: Acute Back Pain}

- One new trial found no difference between traditional Chinese acupuncture versus usual care in mean pain intensity, functional status, or quality of life at 2 to 4 weeks; this was inconsistent with one trial included in the prior report that found acupuncture associated with beneficial effects on pain and function versus usual care. The original report also included trials of Chinese acupuncture versus sham acupuncture that were inconsistent with regard to effects on pain.

\section{KQ 2: Acute Neck Pain}

- No new evidence was found. 


\section{KQ3: Musculoskeletal Pain Not Included in KQ1 or KQ2}

- One new trial found an opioid plus acetaminophen associated with increased likelihood of pain improvement and small decrease in pain intensity at 2 hours versus acetaminophen, although opioids were associated with increased likelihood of any adverse event and drowsiness. No study evaluated this comparison in the original report.

- One new trial evaluated topical ibuprofen versus topical capsaicin but was insufficient to assess comparative effectiveness due to poor quality. No study evaluated this comparison in the original report.

\section{KQ4: Peripheral Neuropathic Pain}

- No new evidence was found.

\section{KQ5: Postoperative Pain}

- One new trial found a multidose course of an opioid plus acetaminophen associated with a small increase in pain intensity versus an NSAID at day 1, with no difference at day 7. The new trial was too small to resolve the inconsistency observed in the original report for this outcome.

- One new trial found a multidose course of an opioid plus acetaminophen associated with no difference versus acetaminophen in pain intensity at day 7; the original report included three trials that each evaluated pain at different time points (none at 1 to $<2$ weeks) and reported inconsistent results.

- One new trial found no statistically significant differences between an opioid agonist (oxycodone) versus a mixed agent (tapentadol) in pain on mobilization or at rest at days 1 to 7 , day 14 , or week 8 ; these findings were consistent with one trial included in the original report.

- One new trial found continuous cooling for 7 days associated with moderate decrease in pain intensity versus usual care at 1 day to 1 week, with no differences at 2 or 6 weeks in pain intensity, function, or quality of life; two new trials reported somewhat inconsistent results for a cold pack for 6 to 24 hours versus usual care in pain intensity at less than 1 day to 1 day. These results are somewhat inconsistent with the original report, which found no differences between cold therapy versus sham therapy in pain intensity and other outcomes at less than 1 week, 2 to less than 4 weeks, or 4 weeks or more, but results are difficult to interpret due to potential differences in the comparators (sham or usual care).

- One new trial found music therapy associated with a small decrease versus no music therapy in pain intensity on day 1 that was not statistically significant; the difference was larger (moderate) and statistically significant on day 4 (3.18 vs. 4.40, $\mathrm{p}=0.006)$. The findings at day 4 were consistent with the original report.

\section{KQ6: Dental Pain}

- One new trial found similar effects of a multidose course of an opioid plus NSAID versus an NSAID on pain intensity at 6 and 24 hours in patients with postoperative dental pain; these findings were consistent with the original report. Although the new trial found the opioid was associated with increased likelihood of a positive global assessment versus the NSAID, an updated meta-analysis that included this trial was consistent with the original report in finding no difference on this outcome. 
- One new trial found similar effects of a multidose course of an opioid alone versus NSAID on pain intensity and likelihood of a positive global assessment in patients with postoperative dental pain; findings were consistent with one trial included in the original report.

- Two new trials found opioid-containing regimens were associated with increased likelihood of harms versus an NSAID alone, including any adverse event, nausea, vomiting, dizziness, and drowsiness; these findings were consistent with the original report.

- One new trial found no difference in pain intensity between a multidose course of an opioid plus acetaminophen versus acetaminophen in patients with acute nonoperative dental pain at less than 1 day or 1 day to less than 1 week, and no difference in rescue analgesic use. This finding was consistent with one small trial included in the original report.

- One new trial found a single dose of an opioid plus acetaminophen associated with small to moderate decrease in pain intensity versus acetaminophen at 4 to 48 hours in patients with acute nonoperative dental pain; statistical significance was not reported, and the new trial was too small to resolve the inconsistency reported for this comparison and outcome in the original report.

- Two new trials found an opioid plus acetaminophen associated with increased likelihood of drowsiness, dizziness, nausea, and vomiting versus acetaminophen; these findings were consistent with the original report.

- One new trial found an NSAID associated with a small decrease in pain intensity at less than 1 day versus acetaminophen; these findings were consistent with the original report.

\section{KQ7: Kidney Stones}

- No new evidence was found.

\section{KQ8: Sickle Cell Crisis}

- No new evidence was found.

\section{Summary of New Evidence}

Table 1 provides the conclusions from the 2020 report and the new findings from studies identified in this update report. Table 1 focuses on KQs and comparisons/outcomes with new evidence; the full strength of evidence (SOE) table is available in the full report (https://www.ncbi.nlm.nih.gov/books/NBK566513/).

Table 1. Summary of conclusions and assessments informed by new evidence

\begin{tabular}{|l|l|l|l|}
\hline Key Question & $\begin{array}{l}\text { Conclusions From 2020 } \\
\text { Report }\end{array}$ & Findings From Update & Assessment \\
\hline $\begin{array}{l}\text { 1 (Low back pain): } \\
\text { Traditional Chinese } \\
\begin{array}{l}\text { acupuncture vs. } \\
\text { sham or usual care }\end{array}\end{array}$ & $\begin{array}{l}\text { Pain at 2 to <4 weeks: } \\
\text { decreased (SOE: Low, } \\
\text { based on 1 RCT) with } \\
\begin{array}{l}\text { acupuncture vs. non- } \\
\text { penetrating sham or usual } \\
\text { care but not needle sham }\end{array}\end{array}$ & $\begin{array}{l}\text { 1 new RCT (n=167) found no } \\
\text { difference between traditional } \\
\text { Chinese acupuncture vs. usual } \\
\text { quality of life at 2 to 4 weeks. }\end{array}$ & $\begin{array}{l}\text { SOE downgraded to } \\
\text { insufficient due to } \\
\text { inconsistency }\end{array}$ \\
\hline
\end{tabular}




\begin{tabular}{|c|c|c|c|}
\hline Key Question & $\begin{array}{l}\text { Conclusions From } 2020 \\
\text { Report }\end{array}$ & Findings From Update & Assessment \\
\hline $\begin{array}{l}3 \text { (Musculoskeletal } \\
\text { pain): Opioid plus } \\
\text { acetaminophen vs. } \\
\text { acetaminophen }\end{array}$ & No evidence. & $\begin{array}{l}\text { One new RCT ( } \mathrm{n}=154) \text { found an } \\
\text { opioid associated with small } \\
\text { decrease in pain but increased } \\
\text { likelihood of adverse events and } \\
\text { drowsiness. }\end{array}$ & $\begin{array}{l}\text { New SOE (no prior } \\
\text { evidence): Low for pain } \\
\text { and adverse events }\end{array}$ \\
\hline $\begin{array}{l}3 \text { (Musculoskeletal } \\
\text { pain): Topical } \\
\text { ibuprofen vs. } \\
\text { capsaicin }\end{array}$ & No evidence. & $\begin{array}{l}\text { One new RCT ( } \mathrm{n}=119) \\
\text { insufficient due to poor quality. }\end{array}$ & $\begin{array}{l}\text { New SOE (no prior } \\
\text { evidence): Insufficient }\end{array}$ \\
\hline $\begin{array}{l}5 \text { (Postoperative } \\
\text { pain): Opioid vs. } \\
\text { NSAID, multidose }\end{array}$ & $\begin{array}{l}\text { Pain, } 1 \text { day to <1 week: } \\
\text { Inconsistent findings } \\
\text { (SOE: insufficient, based on } \\
4 \text { RCTs). } \\
\text { Rescue medication use, } 1 \\
\text { day to <1 week: RR } 1.22 \text { to } \\
2.04 \text { (SOE: moderate, } \\
\text { based on } 4 \text { RCTs) }\end{array}$ & $\begin{array}{l}\text { One new RCT }(n=70) \text { found } \\
\text { opioid associated with a small } \\
\text { increase in pain at day } 1 \text {, with no } \\
\text { difference at day } 7 .\end{array}$ & Unchanged \\
\hline $\begin{array}{l}5 \text { (Postoperative } \\
\text { pain): Opioid vs. } \\
\text { acetaminophen, } \\
\text { multidose }\end{array}$ & $\begin{array}{l}\text { Evidence limited and } \\
\text { inconsistent for pain and } \\
\text { other outcomes; each RCT } \\
\text { evaluated outcomes at a } \\
\text { different time point ( }<1 \text { day, } \\
1 \text { day to }<1 \text { week, and } 2 \text { to } \\
<4 \text { weeks) (SOE: } \\
\text { insufficient, based on } 3 \\
\text { RCTs) }\end{array}$ & $\begin{array}{l}\text { One new RCT }(n=80) \text { found no } \\
\text { difference between an opioid vs. } \\
\text { acetaminophen in pain at day } 7 .\end{array}$ & Unchanged \\
\hline $\begin{array}{l}5 \text { (Postoperative } \\
\text { pain): Opioid vs. } \\
\text { mixed agent }\end{array}$ & $\begin{array}{l}\text { Pain: No difference at <1 } \\
\text { day ( } 1 \mathrm{RCT}, \mathrm{SOE} \text { : low), } 1 \\
\text { day to <1 week ( } 6 \mathrm{RCTs,} \\
\text { SOE: moderate), or } 1 \text { to <2 } \\
\text { weeks ( } 1 \mathrm{RCT} \text {, SOE: low) }\end{array}$ & $\begin{array}{l}\text { One new RCT }(n=91) \text { found no } \\
\text { difference between an opioid vs. } \\
\text { tapentadol in pain at } 1 \text { day to }<1 \\
\text { week, } 1 \text { to }<2 \text { weeks, or } \geq 4 \\
\text { weeks. }\end{array}$ & $\begin{array}{l}\text { SOE unchanged at }<1 \\
\text { day and at } 1 \text { day to }<1 \\
\text { week, upgraded to } \\
\text { moderate for } 1 \text { to }<2 \\
\text { weeks, and assessed } \\
\text { as low for } \geq 4 \text { weeks }\end{array}$ \\
\hline $\begin{array}{l}5 \text { (Postoperative } \\
\text { pain): Cold therapy } \\
\text { vs. sham or no cold } \\
\text { therapy }\end{array}$ & $\begin{array}{l}\text { Pain, <1 week: No } \\
\text { difference (SOE: low, } \\
\text { based on } 3 \text { RCTs) } \\
\text { Pain, function, QoL, } 2 \text { to } \\
\text { <4 weeks and } \geq 4 \text { weeks: } \\
\text { No differences (SOE: low, } \\
\text { based on } 1 \text { RCT) }\end{array}$ & $\begin{array}{l}\text { One new RCT ( } n=100 \text { ) found } \\
\text { continuous cooling for } 7 \text { days } \\
\text { associated with moderate } \\
\text { decrease in pain versus usual } \\
\text { care at } 1 \text { day to }<1 \text { week, with no } \\
\text { differences at } 1 \text { to }<2 \text { weeks or } \geq 4 \\
\text { weeks in pain intensity, function, } \\
\text { or QoL; two new RCTs ( } n=100 \\
\text { and } 137 \text { ) reported inconsistent } \\
\text { results for a cold pack vs. usual } \\
\text { care in pain intensity at }<1 \text { day to } \\
1 \text { day. }\end{array}$ & $\begin{array}{l}\text { SOE unchanged for } \\
\text { cold therapy vs. sham } \\
\text { therapy (no new RCTs) } \\
\text { SOE insufficient (based } \\
\text { on } 2 \text { new RCTs) for } \\
\text { cold therapy vs. usual } \\
\text { care and pain intensity } \\
\text { at }<1 \text { day due to } \\
\text { inconsistency; low } \\
\text { (based on } 1 \text { new } R C T \text { ) } \\
\text { for moderate benefit at } \\
1 \text { day to }<1 \text { week; and } \\
\text { low for no difference at } \\
1 \text { to }<2 \text { weeks and } \geq 4 \\
\text { weeks }\end{array}$ \\
\hline $\begin{array}{l}5 \text { (Postoperative } \\
\text { pain): Music therapy } \\
\text { vs. no music therapy }\end{array}$ & $\begin{array}{l}\text { Pain, }<1 \text { day and } 1 \text { day to } \\
<1 \text { week: Small to } \\
\text { moderate decrease (SOE: } \\
\text { low, based on } 2 \text { RCTs) }\end{array}$ & $\begin{array}{l}\text { One new RCT ( } \mathrm{n}=47 \text { ) found } \\
\text { music therapy associated with a } \\
\text { small decrease in pain intensity } \\
\text { on day } 1 \text { that was not statistically } \\
\text { significant; the difference was } \\
\text { moderate and statistically } \\
\text { significant on day } 4 \text {. }\end{array}$ & $\begin{array}{l}\text { SOE at } 1 \text { day to }<1 \\
\text { week upgraded to } \\
\text { moderate }\end{array}$ \\
\hline
\end{tabular}




\begin{tabular}{|c|c|c|c|}
\hline Key Question & $\begin{array}{l}\text { Conclusions From } 2020 \\
\text { Report }\end{array}$ & Findings From Update & Assessment \\
\hline $\begin{array}{l}6 \text { (Dental pain): } \\
\text { Opioid plus } \\
\text { acetaminophen or } \\
\text { NSAID vs. NSAID, } \\
\text { multidose }\end{array}$ & $\begin{array}{l}\text { Pain, } 1 \text { day to <1 week: No } \\
\text { difference (SOE: low, } \\
\text { based on } 3 \text { RCTs) } \\
\text { Global improvement: No } \\
\text { difference (SOE: low, } \\
\text { based on } 2 \text { RCTs) }\end{array}$ & $\begin{array}{l}\text { One new RCT }(n=620) \text { found } \\
\text { similar effects of a multidose } \\
\text { course of an opioid plus NSAID } \\
\text { vs. an NSAID on pain intensity at } \\
6 \text { and } 24 \text { hours and increased } \\
\text { likelihood of a positive global } \\
\text { assessment. }\end{array}$ & $\begin{array}{l}\text { Unchanged (an } \\
\text { updated meta-analysis } \\
\text { for likelihood of positive } \\
\text { global assessment } \\
\text { again found no } \\
\text { difference) }\end{array}$ \\
\hline $\begin{array}{l}6 \text { (Dental pain): } \\
\text { Opioid vs. NSAID, } \\
\text { multidose }\end{array}$ & $\begin{array}{l}\text { Pain, <1 day and } 1 \text { day to } \\
<1 \text { week: no difference } \\
\text { (SOE: insufficient, based on } \\
1 \mathrm{RCT})\end{array}$ & $\begin{array}{l}\text { One new RCT ( } \mathrm{n}=412) \text { found } \\
\text { similar effects of a multidose } \\
\text { course of an opioid alone vs. } \\
\text { NSAID on pain intensity and } \\
\text { likelihood of a positive global } \\
\text { assessment in patients with } \\
\text { postoperative dental pain. }\end{array}$ & SOE upgraded to low \\
\hline $\begin{array}{l}6 \text { (Dental pain): } \\
\text { Opioid (with or } \\
\text { without } \\
\text { acetaminophen or } \\
\text { NSAID) vS. NSAID }\end{array}$ & $\begin{array}{l}\text { Opioid increased risk of: } \\
\text { Any adverse event: RR } \\
1.72(95 \% \mathrm{Cl} 1.29 \text { to } 2.28) \\
\text { Nausea: RR } 2.72(95 \% \mathrm{Cl} \\
1.84 \text { to } 4.01) \\
\text { Dizziness: RR } 2.97(95 \% \\
\mathrm{Cl} 1.59 \text { to } 5.54) \\
\text { Drowsiness: RR } 1.76(95 \% \\
\mathrm{Cl} 1.00 \text { to } 3.10) \\
\text { (SOE: moderate, based on } \\
9 \text { to } 12 \text { RCTs) }\end{array}$ & $\begin{array}{l}\text { Two new RCTs ( } n=825 \text { and } 60) \\
\text { found opioids associated with } \\
\text { increased risk of any adverse } \\
\text { events, nausea, dizziness, and } \\
\text { drowsiness. }\end{array}$ & Unchanged \\
\hline $\begin{array}{l}6 \text { (Dental pain): } \\
\text { Opioid plus } \\
\text { acetaminophen vs. } \\
\text { acetaminophen, } \\
\text { multidose course }\end{array}$ & $\begin{array}{l}\text { Pain, <1 day: One very } \\
\text { small ( } n=20) \text { RCT found } \\
\text { opioid associated with large } \\
\text { improvement (SOE: } \\
\text { insufficient) }\end{array}$ & $\begin{array}{l}\text { One new RCT }(n=39) \text { found no } \\
\text { differences in pain or rescue } \\
\text { analgesic use among patients } \\
\text { with nonoperative dental pain. }\end{array}$ & $\begin{array}{l}\text { Unchanged (remained } \\
\text { insufficient due to } \\
\text { imprecision and } \\
\text { inconsistency) }\end{array}$ \\
\hline $\begin{array}{l}6 \text { (Dental pain): } \\
\text { Opioid plus } \\
\text { acetaminophen vs. } \\
\text { acetaminophen, } \\
\text { single dose }\end{array}$ & $\begin{array}{l}\text { Pain, <1 day: Inconsistent } \\
\text { effect (SOE: moderate, } \\
\text { based on } 11 \text { RCTs) } \\
\text { Rescue or repeat } \\
\text { medication use, <1 day: } \\
\text { RR } 0.81 \text { ( } 95 \% \text { Cl } 0.56 \text { to } \\
0.97) \text { (SOE: moderate, } \\
\text { based on } 7 \text { RCTs) }\end{array}$ & $\begin{array}{l}\text { One new RCT }(n=60) \text { found an } \\
\text { opioid associated with moderate } \\
\text { to large decrease in pain intensity } \\
\text { versus the NSAID at }<1 \text { day and } \\
1 \text { day to }<1 \text { week, although } \\
\text { statistical significance was not } \\
\text { reported. }\end{array}$ & Unchanged \\
\hline $\begin{array}{l}6 \text { (Dental pain): } \\
\text { Opioid plus } \\
\text { acetaminophen vs. } \\
\text { acetaminophen }\end{array}$ & $\begin{array}{l}\text { Opioids increased risk of: } \\
\text { Any adverse event: RR } \\
1.43 \text { ( } 95 \% \mathrm{Cl} 0.87 \text { to } 2.37) \\
\text { Nausea: RR } 1.55 \text { ( } 95 \% \mathrm{Cl} \\
0.75 \text { to } 3.18) \\
\text { Drowsiness: RR } 2.03(95 \% \\
\text { Cl } 0.70 \text { to } 5.93) \\
\text { Dizziness: RR } 2.49(95 \% \\
\text { Cl } 0.66 \text { to } 9.49) \\
\text { (SOE: low, based on } 4 \text { to } 8 \\
\text { RCTs) }\end{array}$ & $\begin{array}{l}\text { Two new RCTs ( } n=39 \text { and } 60) \\
\text { found opioids associated with } \\
\text { increased risk of any adverse } \\
\text { events ( } 2 \text { RCTs, } 26.6 \% \text { vs. } 0 \% \\
\text { and } 35 \% \text { vs. } 16 \% \text { ), dizziness ( } 1 \\
\text { RCT, } 15 \% \text { vs. } 5 \% \text { ), nauseas ( } 1 \\
\text { RCT, } 40 \% \text { vs. } 11 \% \text { ), and vomiting } \\
\text { (1 RCT, } 10 \% \text { vs. } 0 \% \text { ). }\end{array}$ & Unchanged \\
\hline
\end{tabular}




\begin{tabular}{|c|c|c|c|}
\hline Key Question & $\begin{array}{l}\text { Conclusions From } 2020 \\
\text { Report }\end{array}$ & Findings From Update & Assessment \\
\hline $\begin{array}{l}6 \text { (Dental pain): } \\
\text { NSAID vs. } \\
\text { acetaminophen }\end{array}$ & $\begin{array}{l}\text { Pain intensity, rescue or } \\
\text { repeat medication use: } \\
\text { Moderate to large } \\
\text { decrease } \\
\text { Rescue or repeat } \\
\text { medication use: decrease } \\
\text { (RR } 0.64,95 \% \mathrm{Cl} 0.58 \text { to } \\
0.71 \text { ) (SOE: moderate, } \\
\text { based on } 11 \text { to } 15 \mathrm{RCTS} \text { ) }\end{array}$ & $\begin{array}{l}\text { One new RCT }(n=60) \text { found an } \\
\text { NSAID associated with small } \\
\text { decrease in pain at }<1 \text { day ( } p \text { - } \\
\text { value not reported). }\end{array}$ & Unchanged \\
\hline
\end{tabular}

Abbreviations: $\mathrm{CI}=$ confidence interval; NSAID = nonsteroidal anti-inflammatory drug; QoL = quality of life; RCT = randomized controlled trial; $\mathrm{RR}=$ relative risk; $\mathrm{SOE}=$ strength of evidence

\section{Evidence Details}

\section{Key Question 1: Acute Back Pain}

\section{Acupuncture Versus Usual Care}

The original report included one trial that found traditional Chinese acupuncture associated with decreased likelihood of persistent low back pain versus usual care $(46.9 \%$ vs. $72.1 \%$, relative risk [RR] $0.65,95 \%$ confidence interval [CI] 0.48 to 0.88 ) and increased likelihood of functional improvement ( $74 \%$ vs. $44 \%$, RR $1.66,95 \%$ CI 1.23 to 2.24 ) at 2 to 4 weeks, but there were no differences between acupuncture and usual care on these outcomes at 3 months (SOE: low). The original report also included two trials that compared acupuncture versus different types of sham acupuncture (penetrating or non-penetrating), with somewhat inconsistent results for pain and function (SOE: low).

One new fair-quality trial $(\mathrm{n}=167)$ was inconsistent with the prior trial, as it found no differences between traditional Chinese acupuncture versus usual care in mean pain intensity, functional status, or quality of life at 2 to 4 weeks (at 4 weeks, mean pain intensity 1.8 vs. 1.7, mean Roland Morris Disability Questionnaire score 3 vs. 4; no difference in EQ-5D-3L [data not provided $]^{5}$ ). Estimates for changes in opioid medication use were imprecise, and rates of adverse events were similar between groups. As in the original report, the new trial reported no serious adverse events.

\section{Key Question 2: Acute Neck Pain}

We did not identify any new trials evaluating interventions for acute neck pain.

\section{Key Question 3: Musculoskeletal Pain Not in KQ1 or KQ2}

\section{Opioid Plus Acetaminophen Versus Acetaminophen}

The original report included no trials of an opioid versus acetaminophen for acute musculoskeletal pain. One new good-quality trial $(\mathrm{n}=154)$ compared a single dose of oxycodone $10 \mathrm{mg} /$ acetaminophen $650 \mathrm{mg}$ versus acetaminophen $650 \mathrm{mg}$ in patients with musculoskeletal pain (upper extremities, lower extremities, neck or back, or thorax) who experienced insufficient pain relief after a single dose of ibuprofen $600 \mathrm{mg} .{ }^{6}$ It found the opioid associated with decreased likelihood of pain improvement less than 1.3 points (the predefined threshold for a minimum clinically important difference) on a 0 to 10 scale ( $14 \%$ vs. $32 \%$, RR $0.44,95 \%$ CI 0.23 to 0.83 ) and small decrease in pain intensity at 2 hours ( 4.4 vs. 5.2 , difference $-0.8,95 \% \mathrm{CI}-1.7$ to 0.0 ). 
There was no difference in the proportion of patients who reported that their medication controlled pain ( $78 \%$ vs. $69 \%$, RR 1.13, $95 \%$ CI 0.93 to 1.37 ). Opioids were associated with increased likelihood of any adverse event (34\% vs. 9\%, RR 3.62, 95\% CI 1.67 to 7.82 ) and drowsiness ( $22 \%$ vs. $8.1 \%$, RR $2.76,95 \%$ CI 1.15 to 6.61$)$.

\section{Topical Ibuprofen Versus Topical Capsaicin}

The original report included no trials of topical ibuprofen versus topical capsaicin. One new trial $(\mathrm{n}=119)$ compared topical ibuprofen $5 \%$ versus topical capsaicin $0.5 \%$ three times daily for 3 days in patients with musculoskeletal pain due to blunt upper extremity trauma with no fracture or dislocation. ${ }^{7}$ It was rated poor quality due to high attrition and no intention-to-treat analysis. There was no difference between topical ibuprofen versus topical capsaicin in pain intensity at 2 hours, though there was a small, non-statistically significant difference favoring topical capsaicin at 24 hours ( 3.23 vs. 2.69 on a 0 to 10 scale, $p=0.06$ ) and a moderate, statistically significant difference for topical capsaicin at 72 hours ( 2.68 vs. 1.53 at 72 hours, $p=0.0004$ ). Topical ibuprofen was also associated with decreased likelihood of pain reduction more than 50 percent at 72 hours ( $60 \%$ vs. $84.7 \%$, RR $0.71,95 \%$ CI 0.56 to 0.89 ). Topical ibuprofen was associated with decreased likelihood of any adverse event, although the estimate was imprecise $(10.0 \%$ vs. $18.6 \%$, RR $0.54,95 \%$ CI 0.21 to 1.36$)$; there was no difference in the likelihood of transient skin reactions.

\section{Key Question 4: Peripheral Neuropathic Pain}

We did not identify any new trials evaluating interventions for peripheral neuropathic pain.

\section{Key Question 5: Postoperative Pain}

\section{Opioid Versus NSAID}

The original report found no difference between a single dose of an opioid versus NSAID in pain or rescue medication use at less than 1 day, based on two trials (SOE: low). A multidose course of opioids was associated with increased likelihood of repeat or rescue medication use at 1 day to less than 1 week versus NSAIDs (4 trials, RRs ranged from 1.22 to 2.04), and effects on pain intensity were inconsistent (SOE: moderate for repeat or rescue medication use, insufficient for pain intensity). At 1 week, one trial found an opioid plus NSAID associated with increased rescue medication use and higher, but small and statistically non-significant, increase in pain intensity versus ibuprofen (SOE: low for rescue medication use, insufficient for pain intensity).

One new trial $(\mathrm{n}=70)$ compared a multidose course of hydrocodone $5 \mathrm{mg}$ /acetaminophen 325 $\mathrm{mg}$ versus ibuprofen $400 \mathrm{mg}$ every 4 to 6 hours as needed in patients who underwent rhinoplasty. ${ }^{8}$ Opioids were associated with a small increase in pain intensity at day 1 (2.46 vs. 1.84 on a 0 to 10 scale, $p=0.01$ ), with no difference at day 7 ( 3.14 vs. $3.29, p=0.17$ ). Rescue medication use was not reported. No adverse events were reported in the NSAID arm; other harms were not reported.

\section{Opioid Versus Acetaminophen}

The original report included one trial that found no difference in pain intensity between a single dose of an opioid versus acetaminophen at less than 1 day and no difference in need for remedication, based on one trial (SOE: low). Evidence on the effects of a multidose course of an opioid versus acetaminophen on pain intensity and other outcomes was limited and inconsistent; 
each trial evaluated a different time point ( $<1$ day, 1 day to $<1$ week, or 2 to $<4$ weeks) (SOE: insufficient). Opioids were associated with increased risk of withdrawal due to severe nausea and vomiting versus acetaminophen in one trial and increased risk of withdrawal due to any adverse event in two trials (SOE: low).

One new trial $(n=80)$ compared a multidose course of oxycodone $5 \mathrm{mg}$ /acetaminophen 325 mg 1-2 tabs versus acetaminophen $650 \mathrm{mg}$ every 6 hours as needed in patients who underwent hip arthroscopy. ${ }^{9}$ There were no differences between the opioid versus acetaminophen in pain intensity at 1, 4, and 7 days; the proportion of patients who reported satisfaction with pain relief was very similar between groups (90\% vs. $88 \%)$. No adverse events were reported.

\section{Opioid Versus Mixed Agent}

The original report included one trial that found no difference between an opioid agonist versus mixed agent in pain at less than 1 day ( 1 trial), 1 day to less than 1 week ( 6 trials $)$, or 1 to less than 2 weeks ( 1 trial) (SOE: low to moderate).

One new trial $(\mathrm{n}=91)$ compared the opioid agonist oxycodone (10 mg controlled release) versus the mixed agent tapentadol (50 mg extended release) twice daily in patients who underwent total knee arthroplasty. ${ }^{10}$ There were no statistically significant differences between oxycodone versus tapentadol in pain on mobilization or at rest at days 1 to 7 , day 14, or week 8 . Oxycodone was associated with a lower likelihood of withdrawal due to adverse events, but the estimate was imprecise ( $4 \%$ vs. $17 \%$, RR $0.26,95 \%$ CI 0.57 to 1.14 ).

\section{Cold Therapy Versus Sham or No Cold Therapy}

The original report found no difference between cold therapy versus sham therapy in pain intensity at 1 day to $<1$ week, based on three fair-quality trials (SOE: low). There was also no difference between cold therapy versus sham therapy in pain intensity, function, or quality of life at 2 to less than 4 weeks or 4 weeks or more, based on one good quality trial, although cold therapy was associated with decreased pain medication use in the first 4 days (SOE: low). Seven poor-quality trials identified for the original report did not contribute to the SOE assessments. In the fair- and good-quality trials, the cold therapy intervention varied from an ice pack for 20 minutes twice daily to continuous application using a circulating device for 7 days; in the trials, patients had undergone anterior cruciate ligament reconstruction or total knee arthroplasty.

Three new fair-quality trials $(n=100,100$, and 137$)$ evaluated cold therapy versus usual care for postoperative pain; no new trial compared cold therapy versus sham therapy. Cold therapy consisted of continuous application via a cooling brace with pre-specified temperatures controlled by computer ( 1 trial $\left.^{12}\right)$ or 6 to 24 hours of a cold pack $\left(2\right.$ trials $\left.{ }^{11,13}\right)$. The surgical procedure was total knee arthroplasty in one trial, ${ }^{12}$ cesarean section in one trial, ${ }^{13}$ and laparoscopic hysterectomy in one trial. ${ }^{11}$

One new $(n=100)$ trial compared cold therapy (cooling brace at specified temperatures from day of surgery to postoperative day 7 three times daily) versus usual care following total knee arthroplasty. ${ }^{12}$ At 7 days, cold therapy was associated with moderate decrease in pain intensity at rest $(1.8$ vs. 2.8 on a 0 to 10 scale, $p<0.05)$ and while loading $(2.9$ vs. $4.0, p<0.05)$; there were no statistically significant differences at 2 or 6 weeks on these outcomes. There were no differences in function or quality of life based on the Knee Injury and Osteoarthritis Outcome Score at 2 or 6 weeks. Cold therapy was associated with reduced use of oxycodone $5 \mathrm{mg}$ at day 1 (18\% vs. $52 \%)$ and day $6(11 \%$ vs. $41 \%)$, with a smaller and non-statistically significant difference at day 7 (11\% vs. 24\%). No serious adverse events or withdrawal due to adverse events were reported. 
The other two new trials of cold packs versus usual care reported somewhat inconsistent results, ${ }^{11,13}$ and results are difficult to interpret due to differences in the interventions, timing of follow-up, and populations; in addition, the use of a usual care comparator (rather than sham therapy) makes it difficult to compare results against the trials in the original report. In one trial $(\mathrm{n}=137)$, there was no difference between a cold pack versus usual care following laparoscopic hysterectomy on the Brief Pain Inventory pain severity (median 3.0 vs. 3.3 on a 0 to 10 scale, $\mathrm{p}=0.80$ ) or pain interference (median 2.1 vs. $2.8, \mathrm{p}=0.36)$ at 4 hours. ${ }^{11}$ The other trial $(\mathrm{n}=100)$, which evaluated patients following cesarean section, found a cold pack associated with large decrease in pain intensity versus usual care at 6 to 24 hours (differences ranged from 2.2 to 3.7 points on a 0 to 10 scale) and decreased likelihood of pain 4 or more on a 0 to 10 scale at 24 hours $\left(6 \%\right.$ vs. $\left.38 \%, p<0.001^{13}\right)$. One of the trials ${ }^{11}$ reported a similar rate of any adverse event $(11.6 \%$ vs. $13.2 \%)$, and the other trial ${ }^{13}$ reported no postoperative complications of adverse events from cold compression.

\section{Music Therapy Versus No Music Therapy}

The original report found music therapy was associated with moderate decrease in pain intensity versus no music therapy at less than 1 day (1 trial, hernia repair) and small to moderate decrease in pain intensity at 1 day to less than 1 week ( 1 trial, knee arthroplasty) (SOE: low).

One new, fair-quality trial $(\mathrm{n}=47)$ compared music therapy versus no therapy following knee or hip arthroplasty. ${ }^{14}$ Music therapy was administered 30 minutes three times daily postoperatively in the hospital and for 2 days post-discharge. Music therapy was associated with a small decrease in pain intensity on day 1 that was not statistically significant (5.05 vs. 5.67 on a 0 to 10 scale, $\mathrm{p}=0.21$ ); however, the difference was larger (moderate) and statistically significant on day 4 ( 3.18 vs. $4.40, p=0.006$ ). There was no difference between groups in opioid use. Harms were not reported.

\section{Key Question 6: Dental Pain}

\section{Opioid Versus NSAID}

The original report found a single dose of an opioid plus acetaminophen or NSAID associated with small to moderate increase in pain intensity versus an NSAID at less than 1 day (12 trials), increased likelihood of rescue or repeat medication use (9 trials, RR 1.35, 95\% CI 1.23 to 1.48 ), and decreased likelihood of global improvement ( 5 trials, RR $0.64,95 \%$ CI 0.53 to 0.76 ) (SOE: low for pain intensity and global improvement, moderate for rescue or repeat medication use). There was no difference between a multidose course of therapy with an opioid plus acetaminophen or an NSAID versus an NSAID alone in pain intensity at 1 day to less than 1 week ( 3 trials) or likelihood of global improvement (2 trials, RR $1.15,95 \%$ CI 0.52 to 2.57 ) (SOE: low). There was insufficient evidence to determine effects of a single dose of an opioid alone versus NSAID on pain intensity, due to inconsistent results from six trials; only one trial evaluated a multidose course of an opioid alone versus NSAID (SOE: insufficient). Opioids were associated with increased likelihood of any adverse event (11 trials, pooled RR 1.72, 95\% CI 1.29 to 2.28 ), nausea ( 12 trials, pooled RR $2.72,95 \%$ CI 1.84 to 4.01 ), dizziness ( 10 trials, pooled RR 2.97, 95\% CI 1.59 to 5.54), and drowsiness (9 trials, pooled RR $1.76,95 \%$ CI 1.00 to 3.10) versus an NSAID alone (SOE: moderate). Most trials in the original report evaluated patients with acute postoperative dental pain (most commonly, third molar extraction). In the original report, meta-analysis was not performed for mean pain intensity because results at 
specific time points were estimated in most trials from figures, and standard deviations were not reported; sums of pain intensity differences were not pooled because methods of calculation varied (pain scales utilized and number and timing of assessments).

Two new trials evaluated opioids versus NSAIDs for acute dental pain. ${ }^{15,16}$ The trials differed in terms of opioid dosing (single dose or multidose) and type of dental pain (postoperative versus non-surgical). Both trials evaluated an opioid in combination with an NSAID or acetaminophen; one $^{15}$ of the trials also evaluated an opioid alone.

One new, good-quality trial $(n=825)$ compared a multidose ( 3 doses) course of therapy of three different opioid regimens (tramadol $25 \mathrm{mg} /$ diclofenac $25 \mathrm{mg}$, tramadol $50 \mathrm{mg}$ /diclofenac 50 $\mathrm{mg}$, or tramadol $50 \mathrm{mg}$ ) versus an NSAID (diclofenac) in persons undergoing third molar extraction. ${ }^{15}$ It found both combination regimens associated with larger reduction in pain intensity versus tramadol or diclofenac alone at 4 hours (mean improvement from baseline 5.2 to 5.6 vs. 4.5 on a 0 to 10 scale), but effects of the two regimens were similar at 6 hours (mean improvement ranged from 4.8 to 5.3 points) and 24 hours (mean improvement ranged from 5.7 to 6.0 points). The combination regimens were also associated with larger sum of pain intensity

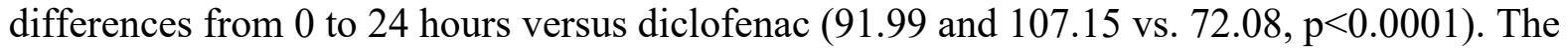
combination regimens were associated with increased likelihood of global assessment "very good" or "excellent" versus diclofenac alone (at 24 hours, $86.6 \%$ and $90.9 \%$ vs. $71.4 \%$ ); as in the original report, an updated meta-analysis found no difference between a multidose course of an opioid plus NSAID or acetaminophen versus NSAID alone in likelihood of global improvement (3 trials, RR 1.17, 95\% CI 0.81 to $1.70, \mathrm{I}^{2}=84 \%$ ). The trial did not report likelihood of rescue or repeat medication use. Effects of tramadol alone versus diclofenac on pain intensity were similar to each other at 4, 6, and 24 hours; there were also no differences in sum of pain intensity differences or likelihood of "good" or "excellent" global assessment (68.8\% vs. 71.4\%).

A smaller new fair-quality trial $(n=60)$ compared a single dose of an opioid plus acetaminophen (tramadol $37.5 \mathrm{mg} /$ acetaminophen $325 \mathrm{mg}$ ) versus an NSAID (ketorolac, $10 \mathrm{mg}$ ) in patients with non-surgical (irreversible pulpitis) acute dental pain. ${ }^{16}$ The opioid was associated with small to moderate decrease in pain intensity versus the NSAID at 4 to 48 hours (mean differences ranged from 0.6 to 1.9 points), although statistical significance was not reported. The trial did not report likelihood of rescue or repeat medication use or likelihood of global improvement.

As in the prior report, the new trials found opioids (with or without an NSAID) were associated with increased likelihood of adverse events versus an NSAID alone, including any adverse event (30.2\% to $51.0 \%$ vs. $23.2 \%$ ), nausea ( $7.3 \%$ to $25.2 \%$ vs. $3.4 \%)$, vomiting (5.9\% to $21.4 \%$ vs. $1.4 \%)$, dizziness ( $5.4 \%$ to $14.1 \%$ vs. $2.9 \%)$, and drowsiness $(26.6 \%$ vs. $0 \%)$.

\section{Opioid Versus Acetaminophen}

The original report found inconsistent effects of an opioid plus acetaminophen versus acetaminophen alone on pain intensity at less than 1 day (11 trials), but an opioid plus acetaminophen was associated with larger sum of pain intensity differences at less than 1 day (10 trials) and decreased likelihood of rescue or repeat medication use ( 7 trials, pooled RR $0.81,95 \%$ CI 0.67 to 0.97 ) (SOE: moderate for sum of pain intensity differences and rescue or repeat medication use). Most trials in the original report evaluated patients with postoperative dental pain (most commonly, third molar extraction). 
Two new fair-quality trials ( $\mathrm{n}=60$ and $\mathrm{n}=39$ ) compared an opioid plus acetaminophen versus acetaminophen alone for acute nonoperative dental pain. ${ }^{16,17}$ One trial ${ }^{16}$ evaluated a single dose and the other tria 17 evaluated a multidose course of therapy.

The first trial $(\mathrm{n}=60)$ compared a single dose of an opioid plus acetaminophen (tramadol $37.5 \mathrm{mg} /$ acetaminophen $325 \mathrm{mg}$ ) versus acetaminophen $(500 \mathrm{mg})$ in patients with nonoperative dental pain (irreversible pulpitis).$^{16}$ The opioid was associated with moderate to large decrease in pain intensity versus acetaminophen at 4 to 48 hours (mean differences ranged from 1.3 to 2.7 points on a 0 to 10 scale), although statistical significance was not reported. The other trial $(n=39)$ found no differences in pain intensity between a 3-day course of codeine 30

$\mathrm{mg}$ /acetaminophen $1,000 \mathrm{mg}$ every 6 hours versus acetaminophen alone in patients with an acute apical abscess (median 5.2 vs. 4.5 at 6 hours, $p=0.33,2.5$ vs. 2.4 at 24 hours, $p=0.61,0.5$ vs. 0 at 3 days, $p=0.25) .{ }^{17}$ There was no difference in the likelihood of rescue analgesic use in the first 48 hours $(25 \%$ vs. $26 \%$ ). Neither trial reported the sum of pain intensity differences.

As in the original report, the new trials found opioids were associated with increased likelihood of drowsiness versus acetaminophen ( $26.6 \%$ vs. $0 \%$ and $35 \%$ vs. $16 \%$ ), dizziness ( $15 \%$ vs. $5 \%$ ), nausea ( $40 \%$ vs. $11 \%$ ), and vomiting (10\% vs. $0 \%)$.

\section{NSAID Versus Acetaminophen}

The original report found a single dose of NSAIDs associated with moderate to large decrease in pain intensity versus acetaminophen at less than 1 day (14 trials) and decreased likelihood of rescue or repeat medication use ( 11 trials, pooled RR $0.64,95 \%$ CI 0.58 to 0.71 ) (SOE: moderate). It also found that NSAIDS might be associated with slightly decreased risk of any adverse event versus acetaminophen ( 12 trials, pooled RR $0.85,95 \%$ CI 0.72 to 1.00 ) (SOE: low). The trials in the original report all evaluated patients with acute postoperative dental pain (third molar extraction in all trials except for one); no trial evaluated a multiday course of therapy.

One new trial $(\mathrm{n}=60)$ that described opioid versus NSAID or acetaminophen comparisons also compared a single dose of NSAID (ketorolac $10 \mathrm{mg}$ ) versus acetaminophen $500 \mathrm{mg}$ for acute nonoperative (apical abscess) dental pain. ${ }^{16}$ The NSAID was associated with a small decrease in pain intensity at 4 hours (3.0 vs. 3.9$)$ and 6 hours ( 4.9 vs. 5.6), although statistical significant was not reported. There were no adverse events (drowsiness or gastritis) with either the NSAID or acetaminophen.

\section{Key Question 7: Kidney Stones (Including Inpatient Management)}

We did not identify any new trials evaluating interventions for kidney stone pain.

\section{Key Question 8: Sickle Cell Crisis (Episodic Pain)}

We did not identify any new trials evaluating interventions for pain associated with acute sickle cell crises.

\section{Conclusions}

The original report evaluated opioid therapy, nonopioid pharmacologic therapies, and nonpharmacologic therapies for selected acute pain conditions. It found that opioid therapy was associated with decreased or similar effectiveness for pain versus an NSAID for surgical dental pain, kidney stone pain, and low back pain. Opioids and NSAIDs were more effective than acetaminophen for surgical dental pain, but opioids were less effective than acetaminophen for 
kidney stone pain. Opioids were associated with increased risk of short-term adverse events versus NSAIDs or acetaminophen, including any adverse event, nausea, dizziness, and somnolence. Serious adverse events were uncommon for all interventions, but studies were not designed to assess risk of overdose, opioid use disorder, or long-term harms. Being prescribed an opioid for acute low back pain or postoperative pain was associated with increased likelihood of use of opioids at long-term followup versus not being prescribed, based on observational studies, although potential confounding could have impacted findings. Evidence on nonpharmacologic therapies was limited, but heat therapy, spinal manipulation, massage, acupuncture, acupressure, a cervical collar, and exercise were effective for specific acute pain conditions. Evidence was limited on the comparative effectiveness of therapies for sickle cell pain, acute neuropathic pain, neck pain, and management of postoperative pain following discharge; effects of therapies for acute pain on non-pain outcomes; effects of therapies on long-term outcomes, including longterm opioid use; and how benefits and harms of therapies vary in subgroups.

New evidence on therapies for acute pain identified for this update was generally consistent with the findings of the original report, with main findings unchanged. For musculoskeletal pain, new evidence enabled an assessment of opioids versus acetaminophen (no evidence in the original report) and suggested that opioids may be associated with a small decrease in pain but increased likelihood of adverse events versus acetaminophen. For postoperative pain, new evidence strengthened findings for no differences between opioids versus mixed agents and beneficial effects of music therapy. Although new evidence was available on acupuncture for low back pain and cold therapy for postoperative pain, findings were difficult to interpret due to differences from the original report with regard to the comparators evaluated (sham or usual care) and interventions. Although new trials of pharmacologic therapy for dental pain (opioids, NSAIDs, or acetaminophen) were generally consistent with the original report, two of the three trials evaluated nonoperative dental pain, which complicates interpretation because the trials in the original report focused on acute postoperative dental pain. More evidence is needed to determine whether effects of pharmacologic therapy differs for acute post-surgical and nonoperative dental pain. New trials were restricted to postoperative pain, dental pain, musculoskeletal pain, and low back pain; therefore, previously identified gaps for sickle cell pain, acute neuropathic pain, and neck pain remain. No new studies were identified on the association between opioid use versus non-use for specific acute pain conditions and short- or long-term opioid use or factors associated with opioid use for specific acute pain conditions.

The next surveillance report is scheduled for February 2022. 


\section{References}

1. Chou R, Wagner J, Ahmed AY, et al. Treatments for Acute Pain: A Systematic Review. Comparative Effectiveness Review No 240. (Prepared by the Pacific Northwest Evidence-based Practice Center under Contract No. 290- 2015-00009-I.) AHRQ Publication No. 20(21)-EHC006. Rockville, MD: Agency for Healthcare Research and Quality; December 2020. DOI: https://doi.org/10.23970/AHRQEPCCER24 0 .

2. Chou R, Dana T, Shetty KD. Testing a Machine Learning Tool for Facilitating Living Systematic Reviews of Chronic Pain Treatments. Methods Research Report. (Prepared by the Pacific Northwest Evidence-based Practice Center under Contract No. 290-2015-00009-I and the Southern California Evidence-based Practice Center-RAND Corporation under Contract No. 290-2015-00010-I.) AHRQ Publication No. 21-EHC004. Rockville, MD: Agency for Healthcare Research and Quality; November 2020. DOI: 10.23970/AHRQEPCMETHTESTINGMAC HINELEARNING.

3. Viswanathan M, Ansari MT, Berkman ND, et al. Assessing the Risk of Bias of Individual Studies in Systematic Reviews of Health Care Interventions. AHRQ Methods Guide for Effectiveness and Comparative Effectiveness Reviews. Rockville, MD: Agency for Healthcare Research and Quality; 2008.

4. Furlan AD, Pennick V, Bombardier C, et al. 2009 updated method guidelines for systematic reviews in the Cochrane Back Review Group. Spine (Phila Pa 1976). 2009;34(18):1929-41. doi: 10.1097/BRS.0b013e3181b1c99f. PMID: 19680101.

5. Skonnord T, Skjeie H, Brekke M, et al. Acupuncture for acute non-specific low back pain: a randomised, controlled, multicentre intervention study in general practice - the Acuback study. BMJ Open. 2020;10(8):e034157. doi: 10.1136/bmjopen2019-034157. PMID: 32764081.

6. Friedman BW, Irizarry E, Feliciano C, et al. A randomized controlled trial of oxycodone/acetaminophen versus acetaminophen alone for emergency department patients with musculoskeletal pain refractory to ibuprofen. Acad Emerg Med. 2021;28(8):859-65. doi:

10.1111/acem.14231. PMID: 33576545.

7. Akgol Gur ST, Dogruyol S, Kocak AO, et al. Topical capsaicin versus topical ibuprofen in acute musculoskeletal injuries: a randomized, double-blind trial. Hong Kong Journal of Emergency Medicine. 2020;00(0):1-7. doi: 10.1177/1024907920975368. PMID: n/a.

8. Frants A, Garber D, Lafer MP, et al. Prospective randomized trial comparing opioids versus nonsteroidal antiinflammatory drugs for postoperative analgesia in outpatient rhinoplasty. Plast Reconstr Surg. 2021;147(1):56-62. doi: 10.1097/PRS.000000000007427. PMID: 33370050 .

9. Bloom DA, Kirby DJ, Thompson K, et al. Effect of acetaminophen on postoperative percocet use in hip arthroscopy: a randomized controlled trial. Arthroscopy. 2021;37(2):530-6. doi: 10.1016/j.arthro.2020.09.046. PMID: 33045334.

10. Rian T, Skogvoll E, Hofstad J, et al. Tapentadol vs oxycodone for postoperative pain treatment the first 7 days after total knee arthroplasty: a randomized clinical trial. Pain. 2021;162(2):396-404. doi: 10.1097/j.pain.0000000000002026. PMID: 32773594 .

11. Cope AG, Wetzstein MM, Mara KC, et al. Abdominal ice after laparoscopic hysterectomy: a randomized controlled trial. J Minim Invasive Gynecol. 2021;28(2):34250.e2. doi: 10.1016/j.jmig.2020.06.027. PMID: 32622918.

12. Brouwers HFG, de Vries AJ, van Zuilen M, et al. The role of computer-assisted cryotherapy in the postoperative treatment after total knee arthroplasty: positive effects on pain and opioid consumption. Knee Surg Sports Traumatol Arthrosc. 2021 doi: 10.1007/s00167-021-06568-x. PMID: 33903923.

13. Suwannalert $\mathrm{P}$, Chanthasenanont A, Pongrojpaw D. Effect of applying cold gel 
pack on reduction of postoperative pain in cesarean section, low midline skin incision: a randomized controlled trial. J Obstet Gynaecol Res. 2021;47(8):2653-8. doi: 10.1111/jog.14855. PMID: 34008228.

14. Laframboise-Otto JM, Horodyski M, Parvataneni HK, et al. A randomized controlled trial of music for pain relief after arthroplasty surgery. Pain Manag Nurs. 2021;22(1):86-93. doi:

10.1016/j.pmn.2020.09.003. PMID: 33129705 .

15. Desjardins P, Alvarado F, Gil M, et al. Efficacy and safety of two fixed-dose combinations of tramadol hydrochloride and diclofenac sodium in postoperative dental pain. Pain Med. 2020;21(10):2447-57. doi: 10.1093/pm/pnaa124. PMID: 32488263.

16. Thota L, Bansal R, Thota G, et al. Efficacy of routinely used analgesics in management of pulpal pain postoperatively a clinical study. J Pharm Bioallied Sci. 2021;13(Suppl 1):S684-S7. doi:

10.4103/jpbs.JPBS_782_20. PMID: 34447181 .

17. da Silva PB, Mendes AT, Cardoso MBF, et al. Comparison between isolated and associated with codeine acetaminophen in pain control of acute apical abscess: a randomized clinical trial. Clin Oral Investig. 2021;25(3):875-82. doi: 10.1007/s00784-

020-03374-6. PMID: 32651644. 


\section{Authors}

Roger Chou, M.D., FACP

Jessica C. Griffin, M.S.

Ian Blazina, M.P.H.

Eli Schwarz, D.D.S., Ph.D., M.P.H.

Chandler Atchison, M.P.H.

Kim Mauer, M.D.

\section{Acknowledgments}

The authors gratefully acknowledge the following individuals for their contributions to this project: research associate Christina Bougatsos, M.P.H., and student research assistant Keeley Black, B.S., both from Oregon Health \& Science University; and Task Order Officer Suchitra Iyer, Ph.D., at the Agency for Healthcare Research and Quality.

\section{Disclaimers}

This report is based on research conducted by the Pacific Northwest Evidence-based Practice Center under contract to the Agency for Healthcare Research and Quality (AHRQ), Rockville, MD (Contract No. 75Q80120D00005). The findings and conclusions in this document are those of the authors, who are responsible for its contents; the findings and conclusions do not necessarily represent the views of AHRQ. Therefore, no statement in this report should be construed as an official position of AHRQ or of the U.S. Department of Health and Human Services.

None of the investigators have any affiliations or financial involvement that conflicts with the material presented in this report.

The information in this report is intended to help healthcare decision makers - patients and clinicians, health system leaders, and policymakers, among others - make well-informed decisions and thereby improve the quality of health care services. This report is not intended to be a substitute for the application of clinical judgment. Anyone who makes decisions concerning the provision of clinical care should consider this report in the same way as any medical reference and in conjunction with all other pertinent information, i.e., in the context of available resources and circumstances presented by individual patients.

This report is made available to the public under the terms of a licensing agreement between the author and the Agency for Healthcare Research and Quality. This report may be used and reprinted without permission except those copyrighted materials that are clearly noted in the report. Further reproduction of those copyrighted materials is prohibited without the express permission of copyright holders.

AHRQ or U.S. Department of Health and Human Services endorsement of any derivative products that may be developed from this report, such as clinical practice guidelines, other quality enhancement tools, or reimbursement or coverage policies, may not be stated or implied.

AHRQ appreciates appropriate acknowledgment and citation of its work. Suggested language for acknowledgment: This work is the first update report of a living systematic review, Treatments for Acute Pain: A Systematic Review, by the Evidence-based Practice Center Program at the Agency for Healthcare Research and Quality (AHRQ).

Suggested citation: Chou R, Griffin JC, Blazina I, Schwarz E, Atchison C, Mauer K. Systematic Review on Treatments for Acute Pain: Surveillance Report 1. (Prepared by the Pacific Northwest Evidence-based Practice Center under Contract No. 75Q80120D00005.) AHRQ Publication No. 22-EHC009. Rockville, MD: Agency for Healthcare Research and Quality; February 2022.

DOI: https://doi.org/10.23970/AHRQEPCSURVEILLANCE1ACUTEPAIN. Posted final reports are located on the Effective Health Care Program search page. 


\section{Afterword}

The Agency for Healthcare Research and Quality (AHRQ), through its Evidence-based Practice Centers (EPCs), sponsors the development of systematic reviews to assist public- and private-sector organizations in their efforts to improve the quality of healthcare in the United States. These reviews provide comprehensive, science-based information on common, costly medical conditions, and new healthcare technologies and strategies.

Systematic reviews are the building blocks underlying evidence-based practice; they focus attention on the strength and limits of evidence from research studies about the effectiveness and safety of a clinical intervention. In the context of developing recommendations for practice, systematic reviews can help clarify whether assertions about the value of the intervention are based on strong evidence from clinical studies. For more information about AHRQ EPC systematic reviews, see https://effectivehealthcare.ahrq.gov/about/epc/evidence-synthesis.

This and future quarterly progress reports will provide up-to-date information about the evidence base to inform health plans, providers, purchasers, government programs, and the healthcare system as a whole on the state of the science. Transparency and stakeholder input are essential to the Effective Health Care Program. Please visit the website (www.effectivehealthcare.ahrq.gov) to see draft research questions and reports or to join an email list to learn about new program products and opportunities for input.

If you have comments on this report, they may be sent by mail to the Task Order Officer named below at: Agency for Healthcare Research and Quality, 5600 Fishers Lane, Rockville, MD 20857, or by email to epc@ahrq.hhs.gov. They will be considered in the next update of the report.

David Meyers, M.D.

Acting Director

Agency for Healthcare Research and Quality

Craig A. Umscheid, M.D., M.S.

Director

Evidence-based Practice Center Program

Center for Evidence and Practice Improvement

Agency for Healthcare Research and Quality
Arlene S. Bierman, M.D., M.S.

Director

Center for Evidence and Practice Improvement

Agency for Healthcare Research and Quality

Suchitra Iyer, Ph.D.

Task Order Officer

Evidence-based Practice Center Program

Center for Evidence and Practice Improvement

Agency for Healthcare Research and Quality 


\section{Appendixes}

Appendix A. Literature Search Strategies ................................................................. A-1

Appendix B. Key Questions and Inclusion and Exclusion Criteria ...................................... B-1

Appendix C. Included Studies List ............................................................................. C-1

Appendix D. Excluded Studies List............................................................................. D-1

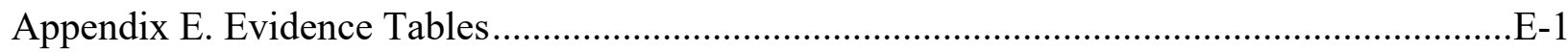

Appendix F. Quality Assessment.................................................................................. 


\section{Appendix A. Literature Search Strategies}

\section{Ovid MEDLINE(R), All 1946 to November 5, 2021}

1. Pain/

2. Acute Pain/

3. Pain Management/

4. (acute adj3 pain).ti,ab,kf.

5. exp back pain/ or exp musculoskeletal pain/ or neck pain/ or exp neuralgia/ or exp Facial Pain/ or exp Nephrolithiasis/ or exp Anemia, Sickle Cell/ or Pain, Postoperative/

6. (back or spine or spinal or radicular or neck or musculoskeletal or fracture* or neuropathic or neuralgia or neuropathy or sciatica or "dental pain" or "ondotogenic pain" or "kidney stone*" or urolithiasis or nephrolithiasis or "sickle cell" or "postoperative pain").ti,ab,kf.

7. treatment outcome/

8. exp Therapeutics/

9. (dh or dt or pc or rh or th).fs.

10. (treatment or therap* or intervention*).ti,ab,kf.

11. (or/1-4) and (5 or 6$)$ and (or/7-10)

12. exp cohort studies/

13. cohort\$.tw.

14. controlled clinical trial.pt.

15. epidemiologic methods/

16. limit 15 to $\mathrm{yr}=1966-1989$

17. exp case-control studies/

18. (case\$ and control\$).tw.

19. or/12-14,16-18

20. randomized controlled trial.pt.

21. (random* or placebo* or control* or trial or blind*).ti,ab.

22. (animals not humans).sh.

23. (comment or editorial or meta-analysis or practice-guideline or review or letter).pt.

24. (20 or 21$) \operatorname{not}(22$ or 23$)$

25. review.pt.

26. (medline or medlars or embase or pubmed or cochrane).tw,sh.

27. (scisearch or psychinfo or psycinfo).tw,sh.

28. (psychlit or psyclit).tw, sh.

29. cinahl.tw,sh.

30. ((hand adj2 search\$) or (manual\$ adj2 search\$)).tw,sh.

31. (electronic database $\$$ or bibliographic database $\$$ or computeri?ed database $\$$ or online database\$).tw, sh.

32. (pooling or pooled or mantel haenszel).tw,sh.

33. (peto or dersimonian or der simonian or fixed effect).tw,sh.

34. or/26-33

35.25 and 34 
36. meta-analysis.pt.

37. meta-analysis.sh.

38. (meta-analys $\$$ or meta analys $\$$ or metaanalys\$).tw,sh.

39. (systematic\$ adj5 review\$).tw,sh.

40. (systematic $\$$ adj5 overview\$).tw,sh.

41. (quantitativ\$ adj5 review\$).tw,sh.

42. (quantitativ\$ adj5 overview\$).tw,sh.

43. (quantitativ\$ adj5 synthesis\$).tw,sh.

44. (methodologic\$ adj5 review\$).tw,sh.

45. (methodologic\$ adj5 overview\$).tw,sh.

46. (integrative research review $\$$ or research integration).tw.

47. or $/ 36-46$

48.35 or 47

49. 19 or 24 or 48

50. 11 and 49

51. or $/ 7-10$

52. or $/ 1-4$

53.51 and 52

54. (ultrasound or TENS or cold or cryotherapy).tw.

55.53 and 54

56. ankle.tw.

57.55 and 56

58.57 not 50

59. limit 58 to english language

60.49 and 59

61. musculoskeletal.tw.

62.55 and 61

63. limit 62 to english language

64. 50 or 63

65.60 or 64

66. (animal* or mouse or mice or rat* or dog* or canine or cow* or bovine or horse* or mare* or pig* or porcine or rabbit* or llama* or sheep or ewe*).ti.

67. 65 not 66

68. (202008\$ or $202009 \$$ or $20201 \$$ or "2020 $08 \$$ " or "2020 $09 \$ "$ or "2020 1\$" or "2020 aug \$" or "2020 sep \$" or "2020 oct \$" or "2020 nov \$" or "2020 dec \$").dp.

69.67 and 68

70. limit 67 to $\mathrm{yr}=" 2021$-Current"

71.69 or 70

Ovid MEDLINE(R), All 1946 to November 5, 2021

Key Question: Post operation pain supplemental search

1. treatment outcome/ 
2. exp Therapeutics/

3. (dh or dt or pc or rh or th).fs.

4. (treatment or therap* or intervention*).ti,ab,kf.

5. Pain, Postoperative/

6. "postoperative pain".ti, ab,kf.

7. 5 or 6

8. or $/ 1-4$

9. 7 and 8

10. (opioid* or hydrocodone or oxycodone or hydromorphone or fentanyl or buprenorphine or naltrexone or naloxone or tramadol or tapentadol).tw.

11. (acetaminophen or "nonsteroidal anti-inflammatory" or NSAID* or "skeletal muscle relaxant*" or SMR* or benzodiazepine* or antidepressant* or anticonvulsant* or cannabis or cannabinoid*).tw.

12. (exercise or "cognitive behavioral therapy" or CBT or meditation or relaxation or music or "virtual reality" or acupuncture or acupressure or electroacupuncture or massage or manipulation or mobilization or mobilisation or "physical modalit*" or "transcutaneous electrical nerve stimulation" or TENS or ultrasound or brace* or traction or heat or cold or cryo*).tw.

13. or $/ 10-12$

14. 9 and 13

15. and (random* or control* or placebo or sham or trial).ti,ab,kf.

16. randomized controlled trial.pt.

17. (random* or placebo* or control* or trial or blind*).ti,ab.

18. (animals not humans).sh.

19. (comment or editorial or meta-analysis or practice-guideline or review or letter).pt.

20. (16 or 17$)$ not (18 or 19)

21.14 and 20

22. 15 or 21

23. (pediatric* or preschool* or toddler* or infan* or child*).ti,ab.

24. 22 not 23

25. limit 24 to english language

26. $(202008 \$$ or $202009 \$$ or $20201 \$$ or "2020 $08 \$$ " or "2020 $09 \$ "$ or "2020 1\$" or "2020 aug \$" or "2020 sep \$" or "2020 oct \$" or "2020 nov \$" or "2020 dec \$").dp.

27. 25 and 26

28. limit 25 to $\mathrm{yr}=" 2021$-Current"

29. 27 or 28

EBM Reviews - Cochrane Central Register of Controlled Trials, October 2021

1. Pain/

2. Acute Pain/

3. Pain Management/

4. (acute adj3 pain).ti,ab. 
5. exp back pain/ or exp musculoskeletal pain/ or neck pain/ or exp neuralgia/ or exp Facial Pain/ or exp Nephrolithiasis/ or exp Anemia, Sickle Cell/ or Pain, Postoperative/

6. (back or spine or spinal or radicular or neck or musculoskeletal or fracture* or neuropathic or neuralgia or neuropathy or sciatica or "dental pain" or "ondotogenic pain" or "kidney stone*" or urolithiasis or nephrolithiasis or "sickle cell" or "postoperative pain").ti,ab.

7. treatment outcome/

8. exp Therapeutics/

9. (dh or dt or pc or rh or th).fs.

10. (treatment or therap* or intervention*).ti,ab.

11. (or/1-4) and (5 or 6$)$ and (or/7-10)

12. limit 11 to medline records

13. 11 not 12

14. conference abstract.pt.

15. "journal: conference abstract".pt.

16. "journal: conference review".pt.

17. or/14-16

18. 13 not 17

19. limit 18 to $\mathrm{yr}=" 2020$-Current"

\section{EBM Reviews - Cochrane Database of Systematic Reviews, 2005 to November 5, 2021}

1. (back or spine or spinal or radicular or neck or musculoskeletal or fracture* or neuropathic or neuralgia or neuropathy or sciatica or "dental pain" or "ondotogenic pain" or "kidney stone*" or urolithiasis or nephrolithiasis or "sickle cell" or "postoperative pain").ti.

2. (treatment or therap* or intervention*).ti,ab.

3. 1 and 2

4. limit 3 to full systematic reviews

5. 4 not chronic.ti.

6. 5 not children.ti.

7. 5 not 6

8. 7 and adult*.ti.

9. 6 or $8(300)$

10. ("2020" or "2021").so.

11.9 and 10

\section{Elsevier Embase, October, 2021}

('backache'/exp OR 'musculoskeletal pain'/exp OR 'neuropathic pain'/exp OR 'neuralgia'/exp OR 'tooth pain'/exp OR 'postoperative pain'/exp OR (('sickle cell anemia'/exp OR 'sickle cell crisis'/exp) AND ('pain'/exp OR pain:ti,ab,kw))) AND 'drug therapy'/exp AND ('article'/it OR 'review'/it) AND 'human'/de AND ('cohort analysis'/de OR 'comparative study'/de OR 'controlled study'/de OR 'meta analysis'/de OR 'randomized controlled trial'/de OR 'randomized controlled trial (topic)'/de OR 'systematic review'/de) AND [english]/lim AND [embase]/lim NOT ([embase]/lim AND [medline]/lim) 


\section{PsycINFO, 1806 to November Week 1, 2021}

1. exp Pain/

2. chronic pain/

3. 1 not 2

4. sickle cell disease/

5. exp Back Pain/

6. exp neuralgia/ or exp peripheral neuropathy/

7. Pain Management/

8. pain.ti,ab.

9. (back or spine or spinal or radicular or neck or musculoskeletal or fracture* or neuropathic or neuralgia or neuropathy or sciatica or dental or ondotogenic or kidney or urolithiasis or nephrolithiasis or "sickle cell" or postoperative).ti,ab.

10. $(7$ or 8$)$ and 9

11. (acute adj3 pain).ti,ab.

12. 3 or 4 or 5 or 6 or 10 or 11

13. exp treatment outcomes/

14. treatment effectiveness evaluation/

15. 12 and (13 or 14)

16. exp clinical trials/

17. (random* or control* or placebo or sham or trial or blind*).ti,ab.

18. 15 and (16 or 17$)$

19. limit 18 to english language

20. limit 19 to human

21. limit 20 to (childhood $<$ birth to 12 years $>$ or adolescence $<13$ to 17 years $>$ )

22. 20 not 21

23. 22 not chronic.ti.

24. limit 23 to $\mathrm{yr}=" 2020$-Current"

Ovid MEDLINE(R) ALL, 1946 to November 5, 2021 Acute Pain Risk

1. Pain/

2. Acute Pain/

3. Pain Management/

4. (acute adj3 pain).ti,ab,kf.

5. exp back pain/ or exp musculoskeletal pain/ or neck pain/ or exp neuralgia/ or exp Facial Pain/ or exp Nephrolithiasis/ or exp Anemia, Sickle Cell/ or Pain, Postoperative/

6. (back or spine or spinal or radicular or neck or musculoskeletal or fracture* or neuropathic or neuralgia or neuropathy or sciatica or "dental pain" or "ondotogenic pain" or "kidney stone*" or urolithiasis or nephrolithiasis or "sickle cell" or "postoperative pain").ti,ab,kf.

7. (or/1-4) and (5 or 6)

8. exp Analgesics, Opioid/

9. opioid*ti,ab,kw. 
10. (buprenorphine or codeine or fentanyl or hydrocodone or hydromorphone or methadone or morphine or oxycodone or oxymorphone or tapentadol or tramadol).ti,ab,kw,sh,hw.

11. or $/ 8-10$

12. exp Opioid-Related Disorders/

13. (opioid adj2 (abuse or addict* or misuse or diversion)).ti,ab,kf.

14. 12 or 13

15.7 and (11 or 14$)$

16. Decision Support Techniques/

17. "Predictive Value of Tests"/

18. Prognosis/

19. Risk Assessment/

20. Risk Factors/

21. Proportional Hazards Models/

22. "Reproducibility of Results"/

23. "Sensitivity and Specificity"/

24. (sensitivity or specificity or accuracy).ti,ab,kf.

25. (risk and (predict\$ or assess\$)).ti,ab,kf.

26. or $/ 16-25$

27. Patient Compliance/

28. Health Services Misuse/

29. Substance Abuse Detection/

30. Drug Monitoring/

31. (urine adj7 (screen\$ or test\$ or detect\$)).ti,ab,kf.

32. Contracts/

33. Patient Education as Topic/

34. Drug Overdose/

35. or $/ 27-34$

36. risk\$.ti,ab,kf.

37. ("risk evaluation and mitigation" or "rems").ti,ab,kf.

38. Risk Reduction Behavior/ or Risk/

39. or $/ 36-38$

40. 26 or 35 or 39

41.15 and 40

42. limit 41 to english language

43. $(202008 \$$ or $202009 \$$ or $20201 \$$ or "2020 $08 \$ "$ or "2020 $09 \$ "$ or "2020 $1 \$ "$ or "2020 aug \$" or "2020 sep \$" or "2020 oct \$" or "2020 nov \$" or "2020 dec \$").dp.

44. 42 and 43

45. limit 42 to $y r=" 2021$-Current"

46. 44 or 45

EBM Reviews - Cochrane Central Register of Controlled Trials, October 2021 Acute Pain Risk

1. Pain/ 
2. Acute Pain/

3. Pain Management/

4. (acute adj3 pain).ti,ab.

5. exp back pain/ or exp musculoskeletal pain/ or neck pain/ or exp neuralgia/ or exp Facial Pain/ or exp Nephrolithiasis/ or exp Anemia, Sickle Cell/ or Pain, Postoperative/

6. (back or spine or spinal or radicular or neck or musculoskeletal or fracture* or neuropathic or neuralgia or neuropathy or sciatica or "dental pain" or "ondotogenic pain" or "kidney stone*" or urolithiasis or nephrolithiasis or "sickle cell" or "postoperative pain").ti,ab.

7. (or/1-4) and (5 or 6)

8. exp Analgesics, Opioid/

9. opioid*.ti,ab,kw.

10. (buprenorphine or codeine or fentanyl or hydrocodone or hydromorphone or methadone or morphine or oxycodone or oxymorphone or tapentadol or tramadol).ti,ab,kw,sh, hw.

11. or $/ 8-10$

12. exp Opioid-Related Disorders/

13. (opioid adj2 (abuse or addict* or misuse or diversion)).ti,ab.

14. 12 or 13

15. 7 and (11 or 14$)$

16. Decision Support Techniques/

17. "Predictive Value of Tests"/

18. Prognosis/

19. Risk Assessment/

20. Risk Factors/

21. Proportional Hazards Models/

22. "Reproducibility of Results"/

23. "Sensitivity and Specificity"/

24. (sensitivity or specificity or accuracy).ti,ab.

25. (risk and (predict\$ or assess $\$$ )).ti,ab.

26. or/16-25

27. Patient Compliance/

28. Health Services Misuse/

29. Substance Abuse Detection/

30. Drug Monitoring/

31. (urine adj7 (screen $\$$ or test $\$$ or detect\$)).ti,ab.

32. Contracts/

33. Patient Education as Topic/

34. Drug Overdose/

35. or/27-34

36. risk\$.ti,ab.

37. ("risk evaluation and mitigation" or "rems").ti,ab.

38. Risk Reduction Behavior/ or Risk/

39. or $/ 36-38$

40.26 or 35 or 39 
41. 15 and 40

42. limit 41 to english language

43. limit 42 to $y r=" 2020$-Current"

\section{Optimized PreMEDLINE Search:}

Ovid MEDLINE(R) In-Process \& In-Data-Review Citations, 1946 to November 5, 2021

1. (acute adj3 pain).ti,ab.

2. (((back or spine or spinal or radicular or neck or musculoskeletal or fracture*) adj3 pain) or neuropathic or neuralgia or neuropathy or sciatica or "dental pain" or "ondotogenic pain" or "kidney stone*" or urolithiasis or nephrolithiasis or "sickle cell" or "postoperative pain").ti.

3. (treatment or therap* or intervention*).ti,ab.

4. (random* or placebo* or control* or trial or blind*).ti,ab.

5. (1 or 2$)$ and 3

6. 4 and 5

7. (202008\$ or $202009 \$$ or $20201 \$$ or "2020 $08 \$$ " or "2020 $09 \$ "$ or "2020 1 " or "2020 aug \$" or "2020 sep \$" or "2020 oct \$" or "2020 nov \$" or "2020 dec \$").dp.

8. 6 and 7

9. limit 6 to $\mathrm{yr}=" 2021$-Current"

10. 8 or 9

11. limit 10 to english language

12. chronic.ti.

13. 11 not 12 


\section{Appendix B. Key Questions and Inclusion and Exclusion Criteria}

\section{Key Questions}

Each Key Question (KQ) for this review focuses on a specific acute pain condition. The conditions and related subquestions are listed below:

KQ1: Acute back pain (including back pain with radiculopathy)

KQ2: Acute neck pain (including neck pain with radiculopathy)

KQ3: Musculoskeletal pain not otherwise included in KQ1 or KQ2 (including fractures)

KQ4: Peripheral neuropathic pain (related to herpes zoster and trigeminal neuralgia)

KQ5: Postoperative pain (excluding inpatient management of pain following major surgical procedures)

KQ6: Dental pain (surgical and nonsurgical)

KQ7: Kidney stones (including inpatient management)

KQ8: Sickle cell crisis (episodic pain)

For each condition above, we addressed the following subquestions:

\section{Opioid Therapy}

a. What is the comparative effectiveness of opioid therapy versus: (1) nonopioid pharmacologic therapy (e.g., acetaminophen, nonsteroidal anti-inflammatory drugs [NSAIDs], antidepressants, anticonvulsants) or (2) nonpharmacologic therapy (e.g., exercise, cognitive behavioral therapy, acupuncture) for outcomes related to pain, function, pain relief satisfaction, and quality of life and after followup at the following intervals: less than 1 day; 1 day to less than 1 week; 1 week to less than 2 weeks; 2 weeks to less than 4 weeks; 4 weeks or longer?

b. How does effectiveness of opioid therapy vary depending on: (1) patient demographics (e.g., age, race, ethnicity, gender); (2) patient medical or psychiatric comorbidities; (3) dose of opioids; (4) duration of opioid therapy, including number of opioid prescription refills and quantity of pills used; (5) opioid use history; (6) substance use history; (7) use of concomitant therapies? 
c. What are the harms of opioid therapy versus nonopioid pharmacologic therapy, or nonpharmacologic therapy with respect to: (1) misuse, opioid use disorder, and related outcomes; (2) overdose; (3) other harms including gastrointestinal-related harms, falls, fractures, motor vehicle accidents, endocrinological harms, infections, cardiovascular events, cognitive harms, and psychological harms (e.g., depression)?

d. How do harms vary depending on: (1) patient demographics (e.g., age, gender); (2) patient medical or psychiatric comorbidities; (3) the dose of opioid used; (4) the duration of opioid therapy; (5) opioid use history; or (6) substance use history?

e. What are the effects of prescribing opioid therapy versus not prescribing opioid therapy for acute pain on 1) short-term ( $<3$ months) continued need for prescription pain relief, such as need for opioid refills, and 2 ) long-term opioid use (3 months or greater)?

f. For patients with acute pain being considered for opioid therapy, what is the accuracy of instruments for predicting risk of opioid misuse, opioid use disorder, or overdose?

g. For patients with acute pain being considered for opioid therapy, what is the effectiveness of instruments for predicting risk of opioid misuse, opioid use disorder, or overdose?

h. For patients with acute pain being considered for opioid therapy, what is the effect of the following factors on the decision to prescribe opioids: (1) existing opioid management plans; (2) patient education; (3) clinician and patient values and preferences related to opioids; (4) urine drug screening; (5) use of prescription drug monitoring program data; (6) availability of close followup?

\section{Nonopioid Pharmacologic Therapy}

i. What is the comparative effectiveness of nonopioid pharmacologic therapy (e.g., acetaminophen, nonsteroidal anti-inflammatory drugs, antidepressants, anticonvulsants) versus: (1) other nonopioid pharmacologic treatments, such as those in a different medication class; or (2) nonpharmacologic therapy for outcomes related to pain, function, pain relief satisfaction, and quality of life after followup at the following intervals: $<1$ day; 1 day to $<1$ week; 1 week to $<2$ weeks; 2 weeks to less than 4 weeks; 4 weeks or longer?

j. How does effectiveness of nonopioid pharmacologic therapy vary depending on:

(1) patient demographics (e.g., age, race, ethnicity, gender); (2) patient medical and psychiatric comorbidities; (3) the type of nonopioid medication; (4) dose of medication; (5) duration of treatment?

k. What are the harms of nonopioid pharmacologic therapy versus other nonopioid pharmacologic therapy or nonpharmacologic therapy with respect to: (1) misuse, (2) overdose; (3) other harms including gastrointestinal-related harms, cardiovascular- 
related harms, kidney-related harms, falls, fractures, motor vehicle accidents, endocrinological harms, infections, cognitive harms, and psychological harms (e.g., depression)?

I. How do harms vary depending on: (1) patient demographics (e.g., age, gender); (2) patient medical comorbidities; (3) the type of nonopioid medication; (4) dose of medication; (5) the duration of therapy?

\section{Nonpharmacologic Therapy}

$\mathrm{m}$. What is the comparative effectiveness of nonpharmacologic therapy versus sham treatment, waitlist, usual care, attention control, and no treatment after followup at the following intervals: less than 1 day; 1 day to less than 1 week; 1 week to less than 2 weeks; 2 weeks to less than 4 weeks; 4 weeks or longer?

n. What is the comparative effectiveness of nonpharmacologic treatments (e.g., exercise, cognitive behavioral therapy, acupuncture) for outcomes related to pain, function, pain relief satisfaction, and quality of life after followup at the following intervals: less than 1 day; 1 day to less than 1 week; 1 week to less than 2 weeks; 2 weeks to less than 4 weeks; 4 weeks or longer?

o. How does effectiveness of nonpharmacologic therapy vary depending on: (1) patient demographics (e.g., age, gender); (2) patient medical and psychiatric comorbidities?

p. How do harms vary depending on: (1) patient demographics (e.g., age, gender);

(2) patient medical and psychiatric comorbidities; (3) the type of treatment used; (4) the frequency of therapy; (5) the duration of therapy? 


\section{Inclusion and Exclusion Criteria}

Table B-1. PICOTS: Inclusion and exclusion criteria

\begin{tabular}{|c|c|c|}
\hline $\begin{array}{l}\text { Picots } \\
\text { Element }\end{array}$ & Include & Exclude \\
\hline Population & $\begin{array}{l}\text { Adults with acute pain related to the following } \\
\text { conditions: } \\
\text { 1. Acute back pain (including back pain with } \\
\text { radiculopathy) } \\
\text { 2. Acute neck pain (including neck pain with } \\
\text { radiculopathy) } \\
\text { 3. Other musculoskeletal pain } \\
\text { 4. Peripheral neuropathic pain (related to herpes } \\
\text { zoster and, trigeminal neuralgia) } \\
\text { 5. Postoperative pain after discharge } \\
\text { 6. Dental pain } \\
\text { 7. Kidney stones } \\
\text { 8. Sickle cell crisis (episodic pain) } \\
\text { *Special populations: } \\
\text { General adult } \\
\text { Older populations }>65 \text { years } \\
\text { - Patients with history of substance use } \\
\text { disorder } \\
\text { Patients currently under treatment for } \\
\text { opioid use disorder with opioid agonist } \\
\text { therapy or naltrexone }\end{array}$ & $\begin{array}{l}\text { Adults with chronic (>3 } \\
\text { months) and subacute pain ( } 6 \\
\text { to } 12 \text { weeks); pain not } \\
\text { associated with one of the } 8 \\
\text { conditions; perioperative pain; } \\
\text { children and adolescents } \\
\text { (<18 years); headache and } \\
\text { cancer pain, diabetic } \\
\text { neuropathic pain, TMJ-related } \\
\text { pain } \\
\text { Mixed chronic/acute or } \\
\text { subacute/acute populations if } \\
\text { study does not report } \\
\text { separate results. }\end{array}$ \\
\hline
\end{tabular}




\begin{tabular}{|c|c|c|}
\hline $\begin{array}{l}\text { Picots } \\
\text { Element }\end{array}$ & Include & Exclude \\
\hline Interventions & $\begin{array}{l}\text { Opioid therapy: } \\
\text { a-e. Any systemic opioid, including agonists, } \\
\text { partial agonists, and mixed mechanism opioids. } \\
\text { f. Instruments, genetic/metabolic tests for } \\
\text { predicting risk of misuse, opioid use disorder, } \\
\text { and overdose } \\
\text { g. Use of risk prediction instruments, } \\
\text { genetic/metabolic tests } \\
\text { h. The following factors: (1) existing opioid } \\
\text { management plans; (2) patient education; (3) } \\
\text { clinician and patient values and preferences } \\
\text { related to opioids; (4) urine drug screening; (5) } \\
\text { use of prescription drug monitoring program } \\
\text { data; (6) availability of close followup } \\
\text { Nonopioid pharmacological therapy: Oral, } \\
\text { parenteral, or topical nonopioid pharmacological } \\
\text { therapy used for acute pain (e.g., } \\
\text { acetaminophen, nonsteroidal anti-inflammatory } \\
\text { drugs, skeletal muscle relaxants, } \\
\text { benzodiazepines, antidepressants, } \\
\text { anticonvulsants, cannabis). } \\
\text { Noninvasive nonpharmacological therapy: } \\
\text { Noninvasive nonpharmacological therapies used } \\
\text { for acute pain (exercise [and related therapies], } \\
\text { cognitive behavioral therapy, meditation, } \\
\text { relaxation, music therapy, virtual reality, } \\
\text { acupuncture, massage, } \\
\text { manipulation/mobilization, physical modalities } \\
\text { [transcutaneous electrical nerve stimulation, } \\
\text { ultrasound, braces, traction, heat, cold]) }\end{array}$ & $\begin{array}{l}\text { Opioid therapy: } \\
\text { a-e. Transdermal patches, } \\
\text { topical opioids } \\
\text { f. Interventions to treat opioid } \\
\text { use disorder, misuse, or } \\
\text { overdose } \\
\text { h. Studies assessing these } \\
\text { factors for effects outside of } \\
\text { the decision to prescribe } \\
\text { opioids }\end{array}$ \\
\hline
\end{tabular}




\begin{tabular}{|c|c|c|}
\hline $\begin{array}{l}\text { Picots } \\
\text { Element }\end{array}$ & Include & Exclude \\
\hline Comparators & $\begin{array}{l}\text { Opioid therapy: } \\
\text { a-d. Usual care, another opioid, nonopioid drug, } \\
\text { or noninvasive, nonpharmacological therapy } \\
\text { e. Usual care, another opioid, nonopioid drug, or } \\
\text { noninvasive, nonpharmacological therapy, no } \\
\text { opioid/nothing prescribed } \\
\text { f. Reference standard for misuse, opioid use } \\
\text { disorder, or overdose; or other benchmarks } \\
\text { g. Usual care } \\
\text { h. Not utilizing the factors specified in } \\
\text { interventions (h) above } \\
\text { Nonopioid pharmacological therapy: } \\
\text { Other nonopioid pharmacological therapy or } \\
\text { noninvasive nonpharmacological therapy } \\
\text { NOTE: Include oral vs. topical NSAID studies as } \\
\text { well as aspirin vs. NSAID studies } \\
\text { Noninvasive nonpharmacological therapy: } \\
\text { Sham treatment, waitlist, usual care, attention } \\
\text { control, and no treatment; or other noninvasive } \\
\text { nonpharmacological therapy }\end{array}$ & $\begin{array}{l}\text { Opioid therapy: } \\
\text { a-d. other comparisons; } \\
\text { placebo; included therapies } \\
\text { vs. excluded therapies; dose } \\
\text { ranging studies } \\
\text { Nonopioid pharm therapy: } \\
\text { placebo; included therapies } \\
\text { vs. excluded therapies; dose } \\
\text { ranging studies; NSAID vs. } \\
\text { NSAID studies; selective } \\
\text { NSAIDs vs. non-selective } \\
\text { NSAIDs } \\
\text { Noninvasive nonpharm } \\
\text { therapy: } \\
\text { historical controls; included } \\
\text { therapies vs. excluded } \\
\text { therapies }\end{array}$ \\
\hline Outcomes & $\begin{array}{l}\text { Opioid therapy: } \\
\text { a-d, g, i. Pain, function, pain relief satisfaction, } \\
\text { and quality of life, harms, adverse events } \\
\text { (including withdrawal, risk of misuse, opioid, } \\
\text { opioid use disorder, overdose). } \\
\text { e. Persistent opioid use } \\
\text { f. Measures of diagnostic accuracy } \\
\text { h. Opioid prescribing rates } \\
\text { Nonopioid therapy: pain, function, pain relief } \\
\text { satisfaction, quality of life and quality of life, } \\
\text { harms, adverse events, opioid use } \\
\text { Noninvasive nonpharmacological therapy: } \\
\text { pain, function, pain relief satisfaction, quality of } \\
\text { life and quality of life, harms, adverse events, } \\
\text { opioid use }\end{array}$ & $\begin{array}{l}\text { Other outcomes; nonclinical } \\
\text { outcomes (e.g., non-harm lab } \\
\text { measures, ROM); measures } \\
\text { of utilization (i.e., costs, } \\
\text { procedures, length of stay, } \\
\text { cost effectiveness/modeling) }\end{array}$ \\
\hline $\begin{array}{l}\text { Time of } \\
\text { followup }\end{array}$ & $\begin{array}{l}\text { At the following intervals: }<1 \text { day; } 1 \text { day to }<1 \\
\text { week; } 1 \text { week to }<2 \text { weeks; } 2 \text { weeks to } 4 \text { weeks; } \\
\geq 4 \text { weeks } \\
\text { NOTE: There will not be exclusion criteria for } \\
\text { duration, unless duration is a matter of minutes. }\end{array}$ & \\
\hline Setting & $\begin{array}{l}\text { Emergency department (initiation of therapy and } \\
\text { following discharge), physician's office, } \\
\text { outpatient or inpatient surgical center, dental } \\
\text { clinic or oral surgery center, inpatient (sickle cell } \\
\text { only) }\end{array}$ & Other settings \\
\hline
\end{tabular}




\begin{tabular}{|l|l|l|}
\hline $\begin{array}{l}\text { Picots } \\
\text { Element }\end{array}$ & Include & Exclude \\
\hline Study design & $\begin{array}{l}\text { All KQs: RCTs; in addition: } \\
\text { e. cohort studies (for long-term opioid use) } \\
\text { f. studies assessing diagnostic accuracy } \\
\text { h. cohort studies and before-after studies } \\
\text { assessing effects on prescribing rates }\end{array}$ & $\begin{array}{l}\text { For all KQs, exclude } \\
\text { uncontrolled observational } \\
\text { studies, case series, and } \\
\text { case reports; studies with } \\
\text { historical controls }\end{array}$ \\
\hline
\end{tabular}

Abbreviations: IV = intravenous; KQ = key question; NSAID = nonsteroidal anti-inflammatory drug; RCT = randomized controlled trial; $\mathrm{ROM}=$ range of motion; $\mathrm{TMJ}=$ temporomandibular joints 


\section{Appendix C. Included Studies List}

1. Akgol Gur ST, Dogruyol S, Kocak AO, et al. Topical capsaicin versus topical ibuprofen in acute musculoskeletal injuries: a randomized, double-blind trial. Hong Kong Journal of Emergency Medicine. 2020;00(0):1-7. doi: 10.1177/1024907920975368. PMID: n/a.

2. Bloom DA, Kirby DJ, Thompson K, et al. Effect of acetaminophen on postoperative percocet use in hip arthroscopy: a randomized controlled trial. Arthroscopy. 2021;37(2):530-6. doi: 10.1016/j.arthro.2020.09.046. PMID: 33045334 .

3. Brouwers HFG, de Vries AJ, van Zuilen M, et al. The role of computer-assisted cryotherapy in the postoperative treatment after total knee arthroplasty: positive effects on pain and opioid consumption. Knee Surg Sports Traumatol Arthrosc. 2021 doi: 10.1007/s00167-021-06568-x. PMID: 33903923.

4. Cope AG, Wetzstein MM, Mara KC, et al. Abdominal ice after laparoscopic hysterectomy: a randomized controlled trial. J Minim Invasive Gynecol. 2021;28(2):34250.e2. doi: 10.1016/j.jmig.2020.06.027. PMID: 32622918.

5. da Silva PB, Mendes AT, Cardoso MBF, et al. Comparison between isolated and associated with codeine acetaminophen in pain control of acute apical abscess: a randomized clinical trial. Clin Oral Investig. 2021;25(3):875-82. doi: 10.1007/s00784020-03374-6. PMID: 32651644.

6. Desjardins P, Alvarado F, Gil M, et al. Efficacy and safety of two fixed-dose combinations of tramadol hydrochloride and diclofenac sodium in postoperative dental pain. Pain Med. 2020;21(10):2447-57. doi: 10.1093/pm/pnaa124. PMID: 32488263.

7. Frants A, Garber D, Lafer MP, et al. Prospective randomized trial comparing opioids versus nonsteroidal antiinflammatory drugs for postoperative analgesia in outpatient rhinoplasty. Plast Reconstr Surg. 2021;147(1):56-62. doi: 10.1097/PRS.0000000000007427. PMID: 33370050 .
8.

Friedman BW, Irizarry E, Feliciano C, et al. A randomized controlled trial of oxycodone/acetaminophen versus acetaminophen alone for emergency department patients with musculoskeletal pain refractory to ibuprofen. Acad Emerg Med. 2021;28(8):859-65. doi: 10.1111/acem.14231. PMID: 33576545.

9. Laframboise-Otto JM, Horodyski M, Parvataneni HK, et al. A randomized controlled trial of music for pain relief after arthroplasty surgery. Pain Manag Nurs. 2021;22(1):86-93. doi: 10.1016/j.pmn.2020.09.003. PMID: 33129705 .

10. Rian T, Skogvoll E, Hofstad J, et al. Tapentadol vs oxycodone for postoperative pain treatment the first 7 days after total knee arthroplasty: a randomized clinical trial. Pain. 2021;162(2):396-404. doi: 10.1097/j.pain.0000000000002026. PMID: 32773594 .

11. Skonnord T, Skjeie H, Brekke M, et al. Acupuncture for acute non-specific low back pain: a randomised, controlled, multicentre intervention study in general practice - the Acuback study. BMJ Open. 2020;10(8):e034157. doi: 10.1136/bmjopen2019-034157. PMID: 32764081.

12. Suwannalert P, Chanthasenanont A, Pongrojpaw D. Effect of applying cold gel pack on reduction of postoperative pain in cesarean section, low midline skin incision: a randomized controlled trial. J Obstet Gynaecol Res. 2021;47(8):2653-8. doi: 10.1111/jog.14855. PMID: 34008228.

13. Thota L, Bansal R, Thota G, et al. Efficacy of routinely used analgesics in management of pulpal pain postoperatively a clinical study. J Pharm Bioallied Sci. 2021;13(Suppl 1):S684-S7. doi: 10.4103/jpbs.JPBS_782_20. PMID: 34447181 . 


\section{Appendix D. Excluded Studies List}

1. Abo Elfadl GM, Osman AM, Ghalyoom $\mathrm{MF}$, et al. Preoperative duloxetine to prevent postoperative shoulder pain after gynecologic laparoscopy: a randomized controlled trial. Braz J Anesthesiol. 2021 doi: 10.1016/j.bjane.2021.07.035. PMID: 34411629. Exclusion reason: Ineligible population

2. Abushanab D, Al-Badriyeh D. Efficacy and safety of ibuprofen plus paracetamol in a fixed-dose combination for acute postoperative pain in adults: meta-analysis and a trial sequential analysis. CNS Drugs. 2021;35(1):105-20. doi: 10.1007/s40263020-00777-7. PMID: 33428176. Exclusion reason: Background only

3. Actrn. A comparison of clinic-delivered and telehealth-delivered post-operative rehabilitation and functional assessment following total knee arthroplasty. http:/www.who.int/trialsearch/Trial2.aspx? TrialID=ACTRN12620001168943. 2020

Exclusion reason: Ineligible publication type/not a study

4. Akdogan M, Utebey G, Atilla HA, et al. Effects of preoperative pregabalin on postoperative pain control in total knee arthroplasty surgery. J Invest Surg. 2021;34(8):848-52. doi: 10.1080/08941939.2019.1704317. PMID: 31913778. Exclusion reason: Ineligible intervention

5. Akpinar KE, Kaya F. Effect of different clinical practices on postoperative pain in permanent mandibular molar teeth with symptomatic apical periodontitis: a randomized controlled clinical trial. Niger J Clin Pract. 2021;24(1):8-16. doi: 10.4103/njcp.njcp_16_20. PMID: 33473019. Exclusion reason: Ineligible intervention

6. Almasri M, Simunovic N, Heels-Ansdell D, et al. Femoroacetabular impingement surgery leads to early pain relief but minimal functional gains past 6 months: experience from the FIRST trial. Knee Surg Sports Traumatol Arthrosc. 2021;29(5):1362-9. doi: 10.1007/s00167020-06401-x. PMID: 33386426. Exclusion reason: Ineligible intervention

7. Alshahrani M, Alghamdi M. Ketamine for sickle cell vaso-occlusive crises: a systematic review. Saudi J Med Med Sci. 2021;9(1):3-9. doi:

10.4103/sjmms.sjmms_218_20. PMID: 33519337. Exclusion reason: Background only

8. Alzahrani H, Mackey M, Stamatakis E, et al. Wearables-based walking program in addition to usual physiotherapy care for the management of patients with low back pain at medium or high risk of chronicity: a pilot randomized controlled trial. PLoS One. 2021;16(8):e0256459. doi: 10.1371/journal.pone.0256459. PMID: 34437607. Exclusion reason: Ineligible population

9. Anger M, Valovska T, Beloeil H, et al. PROSPECT guideline for total hip arthroplasty: a systematic review and procedure-specific postoperative pain management recommendations.

Anaesthesia. 2021;76(8):1082-97. doi: 10.1111/anae.15498. PMID: 34015859.

Exclusion reason: Inadequate duration

10. Ansari AH, Shooshtari Z, Alipour M, et al. What is the effect of pre-emptive oral montelukast on postoperative pain following bimaxillary orthognathic surgery? A tripleblind randomized clinical trial. J Oral Maxillofac Surg. 2021;20:20. doi: 10.1016/j.joms.2021.08.151. PMID: 34547261. Exclusion reason: Ineligible intervention

11. Antony KM, Adams JH, Jacques L, et al. Lidocaine patches for postcesarean pain control in obese women: a pilot randomized controlled trial. Am J Obstet Gynecol MFM. 2021;3(1):100281. doi: 10.1016/j.ajogmf.2020.100281. PMID: 33451596. Exclusion reason: Ineligible comparator

12. Anusitviwat C, Suwanno P, Suwannaphisit $\mathrm{S}$. The effects of vitamin D supplementation in carpal tunnel syndrome treatment outcomes: a systematic review. J Exp Orthop. 2021;8(1)doi: 10.1186/s40634-02100393-4. Exclusion reason: Ineligible intervention

13. Attaar A, Curran M, Meyenburg L, et al. Perioperative pain management and outcomes in patients who-discontinued or continued pre-existing buprenorphine 
therapy. J Opioid Manag. 2021;17(7):33-41.

doi: 10.5055/jom.2021.0640. PMID:

34520024. Exclusion reason: Ineligible intervention

14. Bebee B, Taylor DM, Bourke E, et al. The CANBACK trial: a randomised, controlled clinical trial of oral cannabidiol for people presenting to the emergency department with acute low back pain. Med J Aust. 2021;214(8):370-5. doi: 10.5694/mja2.51014. PMID: 33846971.

Exclusion reason: Ineligible population

15. Bigalke S, Maesen TV, Schnabel K, et al. Assessing outcome in postoperative pain trials: are we missing the point? A systematic review of pain-related outcome domains reported in studies early after total knee arthroplasty. Pain. 2021;162(7):191434. doi: $10.1097 /$ j.pain.0000000000002209. PMID: 33492036. Exclusion reason: Ineligible intervention

16. Bijur PE, Friedman BW, Irizarry E, et al. A randomized trial comparing the efficacy of five oral analgesics for treatment of acute musculoskeletal extremity pain in the emergency department. Ann Emerg Med. 2021;77(3):345-56. doi:

10.1016/j.annemergmed.2020.10.004. PMID: 33358232. Exclusion reason: Ineligible intervention

17. Bloom DA, Baron SL, Luthringer TA, et al. Preoperative opioid education has no effect on opioid use in patients undergoing arthroscopic rotator cuff repair: a prospective, randomized clinical trial. J Am Acad Orthop Surg. 2021;29(19):e961-e8. doi: 10.5435/JAAOS-D-20-00594. PMID: 33306558. Exclusion reason: Ineligible outcome

18. Bloom DA, Manjunath AK, Gotlin MJ, et al. Institutional reductions in opioid prescribing do not change patient satisfaction on Press

Ganey surveys after total shoulder arthroplasty. J Shoulder Elbow Surg. 2021;30(4):858-64. doi: 10.1016/j.jse.2020.07.016. PMID: 32712454. Exclusion reason: Ineligible outcome

19. Bloom DA, Manjunath AK, Gualtieri AP, et al. Patient satisfaction after total hip arthroplasty is not influenced by reductions in opioid prescribing. J Arthroplasty. 2021;36(7S):S250-S7. doi: 10.1016/j.arth.2021.02.009. PMID: 33640183. Exclusion reason: Ineligible comparator

20. Bloom DA, Manjunath AK, Kaplan DJ, et al. Reduced opioid prescribing following arthroscopic meniscectomy does not negatively impact patient satisfaction. Knee. 2021;29:216-21. doi: 10.1016/j.knee.2021.01.020. PMID: 33640620 . Exclusion reason: Ineligible comparator

21. Bojaxhi E, Louie C, ReFaey K, et al. Reduced pain and opioid use in the early postoperative period in patients undergoing a frontotemporal craniotomy under regional vs general anesthesia. World Neurosurg. 2021;150:e31-e7. doi: 10.1016/j.wneu.2021.02.009. PMID: 33684585. Exclusion reason: Ineligible population

22. Bornstein E, Husk G, Lenchner E, et al. Implementation of a standardized postcesarean delivery order set with multimodal combination analgesia reduces inpatient opioid usage. J Clin Med. 2021;10(1):1-10. doi: $10.3390 / \mathrm{jcm} 10010007$. Exclusion reason: Ineligible comparator

23. Brady JT, Dreimiller A, Miller-Spalding S, et al. Are narcotic pain medications necessary after discharge following thyroidectomy and parathyroidectomy? Surgery. 2021;169(1):202-8. doi: 10.1016/j.surg.2020.03.027. PMID: 32416981. Exclusion reason: Ineligible intervention

24. Burns KA, Robbins LM, LeMarr AR, et al. Celecoxib significantly reduces opioid use after shoulder arthroplasty. J Shoulder Elbow Surg. 2021;30(1):1-8. doi: 10.1016/j.jse.2020.08.025. PMID: 32919045. Exclusion reason: Ineligible comparator

25. Buys MJ, Bayless K, Romesser J, et al. Opioid use among veterans undergoing major joint surgery managed by a multidisciplinary transitional pain service. Reg Anesth Pain Med. 2020;45(11):847-52. doi: 10.1136/rapm-2020-101797. PMID: 32848086. Exclusion reason: Ineligible intervention

26. Cashin AG, Folly T, Bagg MK, et al. Efficacy, acceptability, and safety of muscle 
relaxants for adults with non-specific low back pain: systematic review and metaanalysis. BMJ. 2021;374:n1446. doi: 10.1136/bmj.n1446. PMID: 34233900.

Exclusion reason: Background only

27. Chen W, Sun JN, Hu ZH, et al. Cognitive behavioral therapy cannot relieve postoperative pain and improve joint function after total knee arthroplasty in patients aged 70 years and older. Aging Clin Exp Res. 2021 doi: 10.1007/s40520-02101870-7. PMID: 33991330. Exclusion reason: Ineligible population

28. Cheng X, Wang Z, Zhang Y, et al. Oral administration of prednisone effectively reduces subacute pain after total knee arthroplasty. Orthop Traumatol Surgery Res. 2021;107(3):102770. doi:

10.1016/j.otsr.2020.102770. PMID: 33333285. Exclusion reason: Ineligible intervention

29. ChiCtr. A multicenter, randomized, doubleblind, placebo-controlled parallel clinical trial to evaluate the efficacy and safety of ibuprofen injection in the treatment of postoperative acute pain. http:/www.who.int/trialsearch/Trial2.aspx? TrialID=ChiCTR2100042038. 2021.

Exclusion reason: Ineligible publication type/not a study

30. Choudhry NK, Fontanet CP, Ghazinouri R, et al. Design of the spine pain intervention to enhance care quality and reduce expenditure trial (SPINE CARE) study: methods and lessons from a multi-site pragmatic cluster randomized controlled trial. Contemp Clin Trials.

2021;111:106602. doi:

10.1016/j.cct.2021.106602. PMID: 34688915. Exclusion reason: Ineligible publication type/not a study

31. Chuaychoosakoon C, Parinyakhup W, Wiwatboworn A, et al. Comparing postoperative pain between single bundle and double bundle anterior cruciate ligament reconstruction: a retrospective study. BMC Musculoskelet Disord. 2021;22(1):753. doi: 10.1186/s12891-021-04635-5. PMID: 34479511. Exclusion reason: Ineligible intervention

32. Comelon M, Raeder J, Draegni T, et al. Tapentadol versus oxycodone analgesia and side effects after laparoscopic hysterectomy: a randomised controlled trial. Eur $\mathrm{J}$ Anaesthesiol. 2021;38(9):995-1002. doi: 10.1097/EJA.0000000000001425. PMID: 33428347. Exclusion reason: Ineligible population

33. Cooper TE, Hambleton IR, Ballas SK, et al. Pharmacological interventions for painful sickle cell vaso-occlusive crises in adults. Cochrane Database Syst Rev. 2019;2019(11):CD012187. doi: 10.1002/14651858.CD012187.pub2. PMID: 31742673. Exclusion reason: Background only

34. Ctri. Electro acupuncture therapy on carpal tunnel syndrome.

http://www.who.int/trialsearch/Trial2.aspx? TrialID=CTRI. 2020. Exclusion reason: Ineligible publication type/not a study

35. Dalton MK, Chaudhary MA, Andriotti T, et al. Patterns and predictors of opioid prescribing and use after rib fractures. Surgery. 2020;168(4):684-9. doi: 10.1016/j.surg.2020.05.015. PMID: 32653204. Exclusion reason: Ineligible intervention

36. Davey MS, Hurley ET, Anil U, et al. Pain management strategies after anterior cruciate ligament reconstruction: a systematic review with network meta-analysis. Arthroscopy. 2021;37(4):1290-300.e6. doi: 10.1016/j.arthro.2021.01.023. PMID: 33515736. Exclusion reason: Ineligible intervention

37. Davidson ERW, Paraiso MFR, Walters MD, et al. A randomized controlled noninferiority trial of reduced vs routine opioid prescription after prolapse repair. Am J Obstet Gynecol. 2020;223(4):547.e1-.e12. doi: 10.1016/j.ajog.2020.03.017. PMID: 32199926. Exclusion reason: Background only

38. de Oliveira Lima L, Saragiotto BT, Costa LOP, et al. Self-guided web-based pain education for people with musculoskeletal pain: a systematic review and meta-analysis. Phys Ther. 2021;101(10):01. doi: 10.1093/ptj/pzab167. PMID: 34174081. Exclusion reason: Ineligible population

39. de Queiroz VKP, da Nobrega Marinho AM, de Barros GAM. Analgesic effects of a 5\% lidocaine patch after cesarean section: a randomized placebo-controlled double-blind 
clinical trial. J Clin Anesth.

2021;73:110328. doi:

10.1016/j.jclinane.2021.110328. PMID:

33975094. Exclusion reason: Ineligible

compator

40. Delavar P, Foroughian M, Vakilzadeh AK, et al. Effect of acupuncture on the pain of patients with acute low back pain: a randomized double-blind clinical trial study. Koomesh. 2021;23(3):338-46. doi: 10.29252/koomesh.23.3.338. Exclusion

reason: Study covered in included systematic review

41. Derefinko KJ, Gong Z, Bursac Z, et al. Opioid use patterns after primary total knee replacement. Orthop Clin North Am. 2021;52(2):103-10. doi:

10.1016/j.ocl.2020.12.003. PMID:

33752831. Exclusion reason: Ineligible intervention

42. Di Stefano G, Di Lionardo A, Di Pietro G, et al. Pharmacotherapeutic options for managing neuropathic pain: a systematic review and meta-analysis. Pain Res Manag. 2021;2021:6656863. doi:

10.1155/2021/6656863. PMID: 33986899.

Exclusion reason: Ineligible population

43. Fedrigon D, Faris A, Kachroo N, et al. SKOPE-Study of ketorolac vs opioid for pain after endoscopy: a double-blinded randomized control trial in patients undergoing ureteroscopy. J Urol. 2021;206(2):373-81. doi: 10.1097/JU.0000000000001772. PMID: 33819072. Exclusion reason: Ineligible population

44. Fei Y, Huang B, Deng J, et al. Efficacy of dorsal root ganglion pulsed radiofrequency combined with paravertebral injection of recombinant human interferon- $\alpha 2 \mathrm{~b}$ in herpetic neuralgia. J Pain Res. 2021;14:7119. doi: 10.2147/JPR.S290852. PMID: 33732017. Exclusion reason: Ineligible intervention

45. Ferguson MC, Schumann R, Gallagher S, et al. Single-dose intravenous ibuprofen for acute postoperative pain in adults. Cochrane Database Syst Rev. 2021;9:CD013264. doi: 10.1002/14651858.CD013264.pub2. PMID: 34499349. Exclusion reason: Inadequate duration

46. Flowers KM, Patton ME, Hruschak VJ, et al. Conditioned open-label placebo for opioid reduction after spine surgery: a randomized controlled trial. Pain.

2021;162(6):1828-39. doi: 10.1097/j.pain.0000000000002185. PMID: 33449503. Exclusion reason: Ineligible intervention

47. Forlenza EM, Lavoie-Gagne O, Lu Y, et al. Preoperative opioid use predicts prolonged postoperative opioid use and inferior patient outcomes following anterior cruciate ligament reconstruction. Arthroscopy. 2020;36(10):2681-8.e1. doi: 10.1016/j.arthro.2020.06.014. PMID: 32574617. Exclusion reason: Ineligible intervention

48. Fritz JM, Lane E, McFadden M, et al. Physical therapy referral from primary care for acute back pain with sciatica : a randomized controlled trial. Ann Intern Med. 2021;174(1):8-17. doi: 10.7326/M204187. PMID: 33017565. Exclusion reason: Ineligible intervention

49. Gallo G, Grossi U, Di Tanna GL, et al. Short-term outcomes of polycarbophil and propionibacterium acnes lysate gel after open hemorrhoidectomy: a prospective cohort study. J Clin Med. 2020;9(12):3996. doi: 10.3390/jcm9123996. PMID:

33321707. Exclusion reason: Ineligible intervention

50. Geiler K, Schulze M, Inhestern J, et al. The effect of adjuvant oral application of honey in the management of postoperative pain after tonsillectomy in adults: a pilot study. PloS One. 2020;15(2):e0228481. doi: 10.1371/journal.pone.0228481. PMID: 32040956. Exclusion reason: Ineligible intervention

51. Gierthmuehlen M, Jarc N, Plachta DTT, et al. Mastication after craniotomy: pilot assessment of postoperative oral healthrelated quality of life. Acta Neurochir. 2021;19:19. doi: 10.1007/s00701-02105020-w. PMID: 34668078. Exclusion reason: Ineligible population

52. Gorenkov RV, Dadasheva MN, Zolotovskaya IA, et al. Comparative efficacy and tolerance of centrally acting muscle relaxants in elderly patients with nonspecific musculoskeletal pain. Nevrologiya, neiropsikhiatriya, psikhosomatika. 2020;12(1):39-44. doi: 
10.14412/2074-2711-2020-1-39-44.

Exclusion reason: Ineligible comparator

53. Hadad H, Santos AFP, de Jesus LK, et al. Photobiomodulation therapy improves postoperative pain and edema in third molar surgeries: a randomized, comparative, double-blind, and prospective clinical trial. J Oral Maxillofac Surg. 2021;06:06. doi: 10.1016/j.joms.2021.08.267. PMID: 34656515. Exclusion reason: Ineligible intervention

54. Haines KL, Fuller M, Vaughan JG, et al. The impact of nonsteroidal antiinflammatory drugs on older adult trauma patients with hip fractures. J Surg Res. 2020;255:583-93. doi:

10.1016/j.jss.2020.05.064. PMID: 32650142. Exclusion reason: Ineligible intervention

55. Hall M, Dobson F, Plinsinga M, et al. Effect of exercise on pain processing and motor output in people with knee osteoarthritis: a systematic review and meta-analysis. Osteoarthritis Cartilage. 2020;28(12):150113. doi: 10.1016/j.joca.2020.07.009. PMID: 32783909. Exclusion reason: Ineligible population

56. Halvachizadeh S, Stalder AL, Bellut D, et al. Systematic review and meta-analysis of 3 treatment arms for vertebral compression fractures: a comparison of improvement in pain, adjacent-level fractures, and quality of life between vertebroplasty, kyphoplasty, and nonoperative management. JBJS Reviews. 2021;9(10):25. doi: 10.2106/JBJS.RVW.21.00045. PMID: 34695056. Exclusion reason: Ineligible intervention

57. Hamilton DF, Beard DJ, Barker KL, et al. Targeting rehabilitation to improve outcomes after total knee arthroplasty in patients at risk of poor outcomes: randomised controlled trial. BMJ. 2020;371:m3576. doi: 10.1136/bmj.m3576. PMID: 33051212. Exclusion reason: Ineligible population

58. Hanley AW, Gililland J, Erickson J, et al. Brief preoperative mind-body therapies for total joint arthroplasty patients: a randomized controlled trial. Pain. 2021;162(6):1749-57. doi: 10.1097/j.pain.0000000000002195. PMID: 33449510. Exclusion reason: Ineligible intervention

59. Hanley AW, Gililland J, Garland EL. To be mindful of the breath or pain: comparing two brief preoperative mindfulness techniques for total joint arthroplasty patients. J Consult Clin Psychol. 2021;89(7):590-600. doi: 10.1037/ccp0000657. PMID: 34165999. Exclusion reason: Ineligible intervention

60. Hannon CP, Fillingham YA, Browne JA, et al. The efficacy and safety of gabapentinoids in total joint arthroplasty: systematic review and direct meta-analysis. J Arthroplasty. 2020;35(10):2730-8.e6. doi: 10.1016/j.arth.2020.05.033. PMID: 32586656. Exclusion reason: Inadequate duration

61. Hannon CP, Fillingham YA, Nam D, et al. The efficacy and safety of opioids in total joint arthroplasty: systematic review and direct meta-analysis. J Arthroplasty. 2020;35(10):2759-71.e13. doi: 10.1016/j.arth.2020.05.032. PMID: 32571589. Exclusion reason: Inadequate duration

62. Hartwell MJ, Selley RS, Alvandi BA, et al. Reduced opioid prescription after anterior cruciate ligament reconstruction does not affect postoperative pain or prescription refills: a prospective, surgeon-blinded, randomized, controlled trial. Arthrosc Sports Med Rehabil. 2021;3(3):e651-e8. doi: 10.1016/j.asmr.2020.12.012. PMID: 34195628. Exclusion reason: Background only

63. Hendawy HA, Abuelnaga ME. Postoperative analgesic efficacy of ear acupuncture in patients undergoing abdominal hysterectomy: a randomized controlled trial. BMC Anesthesiol. 2020;20(1):279. doi: 10.1186/s12871-02001187-4. PMID: 33167893. Exclusion reason: Ineligible intervention

64. Hosomi K, Sugiyama K, Nakamura Y, et al. A randomized controlled trial of 5 daily sessions and continuous trial of 4 weekly sessions of repetitive transcranial magnetic stimulation for neuropathic pain. Pain. 2020;161(2):351-60. doi: 10.1097/j.pain.0000000000001712. PMID: 31593002. Exclusion reason: Ineligible population 
65. Ilfeld BM, Plunkett A, Vijjeswarapu AM, et al. Percutaneous peripheral nerve

stimulation (neuromodulation) for postoperative pain: a randomized, shamcontrolled pilot study. Anesthesiology. 2021;135(1):95-110. doi: 10.1097/ALN.0000000000003776. PMID: 33856424. Exclusion reason: Ineligible intervention

66. Ilyas AM, Chapman T, Zmistowski B, et al. The effect of preoperative opioid education on opioid consumption after outpatient orthopedic surgery: a prospective randomized trial. Orthopedics. 2021;44(2):123-7. doi: 10.3928/0147744720210201-07. PMID: 33561870. Exclusion reason: Ineligible outcome

67. In T-S, Jung J-H, Jung K-S, et al. Effects of the multidimensional treatment on pain, disability, and sitting posture in patients with low back pain: a randomized controlled trial. Pain Res Manag. 2021;2021:5581491. doi: $10.1155 / 2021 / 5581491$. PMID: 34306274. Exclusion reason: Ineligible population

68. Ince I, Chiu A, Sagir A, et al. Association of pain with atrial fibrillation and delirium after cardiac surgery: a DECADE sub-study. J Cardiothorac Vasc Anesth. 2021;35(10):3021-6. doi: 10.1053/j.jvca.2021.05.013. PMID: 34148803. Exclusion reason: Ineligible intervention

69. Irct20171009036661N. Management of the patients with hip fracture: a comparative study.

http://www.who.int/trialsearch/Trial2.aspx?

TrialID=IRCT20171009036661N4. 2020.

Exclusion reason: Ineligible publication type/not a study

70. Irct20190719044276N. The comparison of effect of pregabalin and duloxetine on postop pain.

http://www.who.int/trialsearch/Trial2.aspx?

TrialID=IRCT20190719044276N1. 2020.

Exclusion reason: Ineligible publication type/not a study

71. Irizarry E, Restivo A, Salama M, et al. A randomized controlled trial of ibuprofen versus ketorolac versus diclofenac for acute, nonradicular low back pain. Acad Emerg Med. 2021;16:16. doi: 10.1111/acem.14321. PMID: 34133820. Exclusion reason:
Ineligible comparator

72. Jacobs BL, Rogers D, Yabes JG, et al. Large reduction in opioid prescribing by a multipronged behavioral intervention after major urologic surgery. Cancer.

2021;127(2):257-65. doi:

10.1002/cncr.33200. PMID: 33002197.

Exclusion reason: Ineligible study design

73. Jacobus D, Mehr S, Ziccardi V. Liposomal bupivacaine use in exploratory lingual nerve microsurgery: does liposomal bupivacaine use decrease postoperative pain and opioid consumption compared to bupivacaine hydrochloride? A pilot study. Quintessence Int. 2021;52(9):812-8. doi: 10.3290/j.qi.b1763651. PMID: 34269041. Exclusion reason: Ineligible intervention

74. Jarecki J, Sobiech M, Turzanska K, et al. A kinesio taping method applied in the treatment of postsurgical knee swelling after primary total knee arthroplasty. J Clin Med. 2021;10(13):2992. doi: 10.3390/jcm10132992. PMID: 34279474. Exclusion reason: Ineligible study design

75. Javaid S, Shafi M, Lodhi Y. Comparison of postoperative pain in photorefractive keratectomy using topical versus oral nonsteroidal anti-inflammatory drugs. Anaesth Pain Intensive Care. 2021;25(3):324-8. doi: 10.35975/apic.v25i3.1527. Exclusion reason: Ineligible intervention

76. Jildeh TR, Okoroha KR, Kuhlmann N, et al. Multimodal nonopioid pain protocol provides equivalent pain versus opioid control following meniscus surgery: a prospective randomized controlled trial. Arthroscopy. 2021;37(7):2237-45. doi: 10.1016/j.arthro.2021.02.043. PMID: 33713756. Exclusion reason: Ineligible intervention

77. Kano K, Kawamura K, Miyake T. Effects of preemptive analgesia with intravenous acetaminophen on postoperative pain relief in patients undergoing third molar surgery: a prospective, single-blind, randomized controlled trial. Med Oral Patol Oral Cir Bucal. 2021;26(1):e64-e70. doi: 10.4317/medoral.23983. PMID: 33037803. Exclusion reason: Ineligible intervention

78. Karlsson M, Bergenheim A, Larsson MEH, et al. Effects of exercise therapy in patients 
with acute low back pain: a systematic review of systematic reviews. Syst Rev. 2020;9(1):182. doi: 10.1186/s13643-02001412-8. PMID: 32795336. Exclusion reason: Inadequate duration

79. Khaw D, Bucknall T, Considine J, et al. Sixyear trends in postoperative prescribing and use of multimodal analgesics following total hip and knee arthroplasty: a single-site observational study of pain management. Eur J Pain. 2021;25(1):107-21. doi: 10.1002/ejp.1652. PMID: 32969139. Exclusion reason: Ineligible intervention

80. Kim D, Lee YJ, Park KS, et al. The effectiveness and cost-effectiveness of motion style acupuncture treatment (MSAT) for acute neck pain: a multi-center randomized controlled trial. Medicine (Baltimore). 2020;99(44):e22871. doi: 10.1097/MD.0000000000022871. PMID: 33126334. Exclusion reason: Ineligible study design

81. Kim MG, Kim MY. Effects of kinesiology tape after enucleation of mandibular dentigerous cysts. J Korean Assoc Oral Maxillofac Surg. 2020;46(2):108-15. doi: 10.5125/JKAOMS.2020.46.2.108. PMID: 32364350. Exclusion reason: Ineligible intervention

82. Kim MS, Koh IJ, Choi KY, et al. Efficacy of duloxetine compared with opioid for postoperative pain control following total knee arthroplasty. PLoS One 2021;16(7):e0253641. doi: 10.1371/journal.pone.0253641. PMID: 34214098. Exclusion reason: Ineligible outcome

83. Kim MS, Koh IJ, Sung YG, et al. Preemptive duloxetine relieves postoperative pain and lowers wound temperature in centrally sensitized patients undergoing total knee arthroplasty: a randomized, double-blind, placebocontrolled trial. J Clin Med. 2021;10(13):2809. doi: 10.3390/jcm10132809. PMID: 34202314. Exclusion reason: Ineligible intervention

84. Kondo Y, Yoshida Y, Iioka T, et al. Shortterm effects of isometric quadriceps muscle exercise with auditory and visual feedback on pain, physical function, and performance after total knee arthroplasty: a randomized controlled trial. J Knee Surg. 2020 doi: 10.1055/s-0040-1721035. PMID: 33241542. Exclusion reason: Ineligible intervention

85. Kong M, Li X, Shen J, et al. The effectiveness of preemptive analgesia for relieving postoperative pain after videoassisted thoracoscopic surgery (VATS): a prospective, non-randomized controlled trial. J Thorac Dis. 2020;12(9):4930-40. doi: 10.21037/jtd-20-2500. PMID: 33145067.

Exclusion reason: Ineligible intervention

86. Koppenhaver SL, Weaver AM, Randall TL, et al. Effect of dry needling on lumbar muscle stiffness in patients with low back pain: a double blind, randomized controlled trial using shear wave elastography. J Man Manip Ther. 2021:1-11. doi: 10.1080/10669817.2021.1977069. PMID: 34525901. Exclusion reason: Ineligible population

87. Kumar V, Reddy ED, Shekhar C, et al. Open cholecystectomy versus laparoscopic cholecystectomy: a comparative study at north Indian based teaching hospital. Eur J Mol Clin Med. 2021;8(4):586-91. Exclusion reason: Ineligible intervention

88. Kunze KN, Polce EM, Lilly DT, et al. Adjunct analgesia reduces pain and opioid consumption after hip arthroscopy: a systematic review of randomized controlled trials. Am J Sports Med. 2020;48(14):363851. doi: 10.1177/0363546520905884. PMID: 32119562 . Exclusion reason: Inadequate duration

89. Lam L, Richardson MG, Zhao Z, et al. Enhanced discharge counseling to reduce outpatient opioid use after cesarean delivery: a randomized clinical trial. Am J Obstet Gynecol MFM. 2021;3(1):100286. doi: 10.1016/j.ajogmf.2020.100286. PMID: 33451618. Exclusion reason: Background only

90. Lanzkron S, Little J, Wang H, et al. Treatment of acute pain in adults with sickle cell disease in an infusion center versus the emergency department: a multicenter prospective cohort study. Ann Intern Med. 2021;174(9):1207-13. doi: 10.7326/M207171. PMID: 34224261. Exclusion reason: Ineligible intervention

91. Lee CW, Lo YT, Devi S, et al. Gender differences in preoperative opioid use in spine surgery patients: a systematic review 
and meta-analysis. Pain Med.

2020;21(12):3292-300. doi:

10.1093/pm/pnaa266. PMID: 32989460.

Exclusion reason: Ineligible population

92. Lee Y, Kim K. Factors related to the consumption of patient-controlled postoperative analgesics in Korea: a retrospective study. Pain Manag Nurs. 2020;21(5):449-55. doi:

10.1016/j.pmn.2019.09.006. PMID: 31859054. Exclusion reason: Ineligible intervention

93. Leroux EJ, Kaufman EA, Kontaxis CN, et al. Intensive cryotherapy in the emergency department (ICED): a randomized controlled trial. West J Emerg Med. 2021;22(2):445-9. doi: $10.5811 /$ westjem.2020.10.48831. PMID: 33856337. Exclusion reason: Ineligible intervention

94. Li WT, Bell KL, Yayac M, et al. A postdischarge multimodal pain management cocktail following total knee arthroplasty reduces opioid consumption in the 30-day postoperative period: a group-randomized trial. J Arthroplasty. 2021;36(1):164-72.e2. doi: 10.1016/j.arth.2020.07.060. PMID: 33036845. Exclusion reason: Ineligible intervention

95. Liampas A, Rekatsina M, Vadalouca A, et al. Pharmacological management of painful peripheral neuropathies: a systematic review. Pain Ther. 2021;10(1):55-68. doi: 10.1007/s40122-020-00210-3. PMID: 33145709. Exclusion reason: Ineligible population

96. Liu C, Abdel Shaheed C, Braten LC, et al. Antibiotic treatment for low back pain or radicular pain, or both. Cochrane Database Syst Rev. 2021;2021(9)doi: 10.1002/14651858.CD014221. Exclusion reason: Ineligible publication type/not a study

97. Liu X, Wei L, Zeng Q, et al. The treatment of topical drugs for postherpetic neuralgia: a network meta-analysis. Pain Physician. 2020;23(6):541-51. PMID: 33185370.

Exclusion reason: Ineligible population

98. Mammoto T, Fujie K, Taguchi N, et al. Short-term effects of early postoperative celecoxib administration for pain, sleep quality, and range of motion after total knee arthroplasty: a randomized controlled trial. J
Arthroplasty. 2021;36(2):526-31. doi: 10.1016/j.arth.2020.08.018. PMID: 32900564. Exclusion reason: Ineligible intervention

99. Marchand DK, Argaez C. CADTH Health Technology Review. Canadian Agency for Drugs and Technologies in Health. 2021 PMID: 34185448. Exclusion reason: Background only

100. Martins-de-Barros AV, Barros AM, Siqueira AK, et al. Is dexamethasone superior to ketorolac in reducing pain, swelling and trismus following mandibular third molar removal? A split mouth triple-blind randomized clinical trial. Med Oral Patol Oral Cir Bucal. 2021;26(2):e141-e50. doi: 10.4317/medoral.24088. PMID: 33247572.

Exclusion reason: Ineligible intervention

101. Massie L, Gunaseelan V, Waljee J, et al. Relationship between initial opioid prescription size and likelihood of refill after spine surgery. Spine J. 2021;21(5):772-8. doi: 10.1016/j.spinee.2021.01.016. PMID: 33460812. Exclusion reason: Ineligible comparator

102. McNicol ED, Ferguson MC, Schumann R. Single-dose intravenous ketorolac for acute postoperative pain in adults. Cochrane Database Syst Rev. 2021;5:CD013263. doi: 10.1002/14651858.CD013263.pub2. PMID: 33998669. Exclusion reason: Inadequate duration

103. Miranda JP, Silva WT, Silva HJ, et al. Effectiveness of cryotherapy on pain intensity, swelling, range of motion, function and recurrence in acute ankle sprain: a systematic review of randomized controlled trials. Phys Ther Sport.

2021;49:243-9. doi: 10.1016/j.ptsp.2021.03.011. PMID: 33813154. Exclusion reason: Background only

104. Mohajerani H, Tabeie F, Alirezaei A, et al. Does combined low-level laser and lightemitting diode light irradiation reduce pain, swelling, and trismus after surgical extraction of mandibular third molars? A randomized double-blinded crossover study. J Oral Maxillofac Surg. 2021;79(8):1621-8. doi: 10.1016/j.joms.2020.07.017. PMID: 32780994. Exclusion reason: Ineligible comparator 
105. Monteiro LPB, Guerreiro MYR, de Castro

Valino R, et al. Effect of intracanal cryotherapy application on postoperative endodontic pain: a systematic review and metaanalysis. Clin Oral Investig. 2021;25(1):23-35. doi: 10.1007/s00784-02003693-8. PMID: 33222053. Exclusion reason: Systematic review or meta-analysis used as a source document

106. Moore AR, Derry S, Aldington D, et al. Adverse events associated with single dose oral analgesics for acute postoperative pain in adults - an overview of Cochrane reviews. Cochrane Database Syst Rev. 2015;2015(10):CD011407. doi: 10.1002/14651858.CD011407.pub2. PMID: 26461263. Exclusion reason: Background only

107. Moore L, Norwood C, Stackhouse R, et al. Gabapentin reduces postoperative pain and opioid consumption in patients who underwent lumbar laminectomy. J Am Pharm Assoc (2003). 2021;61(5):e78-e83. doi: 10.1016/j.japh.2021.05.002. PMID: 34024754. Exclusion reason: Ineligible population

108. Moutzouros V, Jildeh TR, Tramer JS, et al. Can we eliminate opioids after anterior cruciate ligament reconstruction? A prospective, randomized controlled trial. Am J Sports Med. 2021 doi:

10.1177/03635465211045394. PMID: 34668795. Exclusion reason: Ineligible intervention

109. Murillo C, Treleaven J, Cagnie B, et al. Effects of dry needling of the obliquus capitis inferior on sensorimotor control and cervical mobility in people with neck pain: a double-blind, randomized sham-controlled trial. Braz J Phys Ther. 2021;05:05. doi: 10.1016/j.bjpt.2021.07.005. PMID: 34535409. Exclusion reason: Ineligible population

110. Myrick R, Blakemore S, Waite E, et al. Outpatient pain clinic and intranasal fentanyl to improve sickle cell disease outcomes. Pediatr Blood Cancer. 2020;67(10):e28648. doi:

10.1002/pbc.28648. PMID: 32798305. Exclusion reason: Ineligible intervention

111. Nalamachu S, Pergolizzi J, Kaye R. Tolperisone for the treatment of acute muscle spasm of the back: results from the dose-ranging phase 2 STAR Study (NCT03802565). J Pain Res. 3059;13:305969. doi: $10.2147 /$ JPR.S278857. PMID: 33262641. Exclusion reason: Ineligible comparator

112. Nikolakopoulou E, Tzefronis D, Kanavos K, et al. Evaluation of oral use of dexketoprofen/tramadol in acute postoperative pain in patients undergoing total hip replacement with a minimally invasive anterior approach (amis). Pain Pract. 2020;20(SUPPL 1):51. Exclusion reason: Ineligible comparator

113. Noori A, Sprague S, Bzovsky S, et al. Predictors of long-term pain after hip arthroplasty in patients with femoral neck fractures: a cohort study. J Orthop Trauma. 2020;34 Suppl 3:S55-S63. doi: 10.1097/BOT.0000000000001929. PMID: 33027167. Exclusion reason: Ineligible intervention

114. Olausson A, Svensson J, Andrell P, et al. Total opioid-free general anaesthesia can improve postoperative outcomes after surgery, without evidence of adverse effects on patient safety and pain management: a systematic review and meta-analysis. Acta Anaesthesiol Scand. 2021;01:01. doi: 10.1111/aas.13994. PMID: 34724195. Exclusion reason: Ineligible intervention

115. Otao G, Maruta T, Tsuneyoshi I. Comparison of opioid local anesthetic combination regimens using the number of self-administrated boluses in patientcontrolled epidural analgesia after cesarean section: a retrospective single-center study. Medicine (Baltimore).

2021;100(17):e25560. doi: 10.1097/MD.0000000000025560. PMID: 33907103. Exclusion reason: Ineligible intervention

116. Pace M, Gannon K, Friedland M, et al. Influence of inpatient opioid consumption on persistent use following total knee arthroplasty. Reg Anesth Pain Med. 2021;46(2):99-103. doi: 10.1136/rapm2020-101582. PMID: 33172905. Exclusion reason: Ineligible intervention

117. Pal S, Dixit R, Moe S, et al. Transcutaneous electrical nerve stimulation (TENS) for pain management in sickle cell disease. Cochrane Database Syst Rev. 2020;3(3):CD012762. doi: 10.1002/14651858.CD012762.pub2. 
PMID: 32124977. Exclusion reason:

Background only

118. Park S, Nahm FS, Han WK, et al. The 5\% lidocaine patch for decreasing postoperative pain and rescue opioid use in sternotomy: a prospective, randomized, double-blind trial. Clin Ther. 2020;42(12):2311-20. doi: 10.1016/j.clinthera.2020.10.011. PMID: 33223228. Exclusion reason: Ineligible population

119. Parseliunas A, Paskauskas S, Kubiliute E, et al. Transcutaneous electric nerve stimulation reduces acute postoperative pain and analgesic use after open inguinal hernia surgery: a randomized, double-blind, placebo-controlled trial. J Pain.

2021;22(5):533-44. doi:

10.1016/j.jpain.2020.11.006. PMID:

33309784. Exclusion reason: Ineligible intervention

120. Paskey T, Vincent S, Critchlow E, et al. Prospective randomized study evaluating the effects of preoperative opioid counseling on postoperative opioid use after outpatient lower extremity orthopaedic surgery. Journal of Surgical Orthopaedic Advances. 2021;30(1):2-6. PMID: 33851905.

Exclusion reason: Ineligible intervention

121. Patel AA, Walker CT, Prendergast V, et al. Patient-controlled analgesia following lumbar spinal fusion surgery is associated with increased opioid consumption and opioid-related adverse events. Neurosurgery. 2020;87(3):592-601. doi:

10.1093/neuros/nyaa111. PMID: 32357244.

Exclusion reason: Ineligible population

122. Pereira VBP, Torriceli AAM, Garcia R, et al. Codeine plus acetaminophen improve sleep quality, daily activity level, and food intake in the early postoperative period after photorefractive keratectomy: a secondary analysis. Arq Bras Oftalmol. 2021;84(1):4550. doi: 10.5935/0004-2749.20210008. PMID: 33470341. Exclusion reason: Ineligible comparator

123. Pergolizzi JV, Magnusson P, LeQuang JA, et al. Can NSAIDs and acetaminophen effectively replace opioid treatment options for acute pain? Expert opinion on pharmacotherapy. 2021;22(9):1119-26. doi: 10.1080/14656566.2021.1901885. PMID: 33689517. Exclusion reason: Ineligible publication type/not a study
124. Pius AK, Jones E, Bonnell LN, et al. Patients' experience with opioid pain medication after discharge from surgery: a mixed-methods study. J Surg Res. 2020;256:328-37. doi: 10.1016/j.jss.2020.06.026. PMID: 32731094. Exclusion reason: Ineligible intervention

125. Plewniak KM, Kintzer E, Eisenberg R, et al. Examining reduced opioid prescriptions after gynecologic laparoscopy: a randomized controlled trial. J Minim Invasive Gynecol. 2021;28(2):366-73. doi: 10.1016/j.jmig.2020.07.001. PMID: 32652243. Exclusion reason: Background only

126. Potnuru PP, Patel SD, Birnbach DJ, et al. Effects of state law limiting postoperative opioid prescription in patients after cesarean delivery. Anesth Analg. 2021;132(3):75260. doi: 10.1213/ANE.0000000000004993. PMID: 32639388. Exclusion reason: Ineligible outcome

127. Pritchard KT, Baillargeon J, Raji MA, et al. Association of occupational and physical therapy with duration of prescription opioid use after hip or knee arthroplasty: a retrospective cohort study of Medicare enrollees. Arch Phys Med Rehabil. 2021;102(7):1257-66. doi: 10.1016/j.apmr.2021.01.086. PMID: 33617862. Exclusion reason: Ineligible intervention

128. Roofthooft E, Joshi GP, Rawal N, et al. PROSPECT guideline for elective caesarean section: updated systematic review and procedure-specific postoperative pain management recommendations. Anaesthesia. 2021;76(5):665-80. doi: 10.1111/anae.15339. PMID: 33370462. Exclusion reason: Inadequate duration

129. Rubin MA, Stark NF, Harsmar SJC, et al. Pre-operative epidural analgesia in hip fracture patients - a systematic review and meta-analysis. Acta Anaesthesiol Scand. 2021;65(5):578-89. doi: 10.1111/aas.13760. PMID: 33296497. Exclusion reason: Ineligible intervention

130. Ruddell JH, Reid DBC, Shah KN, et al. Larger initial opioid prescriptions following total joint arthroplasty are associated with greater risk of prolonged use. J Bone Joint Surg Am. 2021;103(2):106-14. doi: 
10.2106/JBJS.20.00732. PMID: 33074953.

Exclusion reason: Ineligible outcome

131. Said AM, Zubovic E, Ha AY, et al. Effects of single-dose preoperative pregabalin on postoperative pain and opioid consumption in cleft orthognathic surgery. J Craniofac Surg. 2021;32(2):517-20. doi: 10.1097/SCS.0000000000007109. PMID: 33704973. Exclusion reason: Ineligible intervention

132. Santini M, Da Rosa RA, Ferreira MB, et al. Medications used for prevention and treatment of postoperative endodontic pain: a systematic review. Eur Endod J. 2021;6(1):15-24. doi:

10.14744/eej.2020.85856. PMID: 33609020.

Exclusion reason: Background only

133. Sbardella S, La Russa C, Bernetti A, et al. Muscle energy technique in the rehabilitative treatment for acute and chronic non-specific neck pain: a systematic review. Healthcare (Basel). 2021;9(6):746. doi: 10.3390/healthcare9060746. PMID: 34204590. Exclusion reason: Ineligible intervention

134. Scott G, Gong J, Kirkpatrick C, et al. Systematic review and meta-analysis of oral paracetamol versus combination oral analgesics for acute musculoskeletal injuries. Emerg Med Australas. 2021;33(1):107-13. doi: 10.1111/17426723.13596. PMID: 32864884. Exclusion reason: Background only

135. Selley RS, Hartwell MJ, Alvandi BA, et al. Risk factors for increased consumption of narcotics after hip arthroscopy: a prospective, randomized control trial. J Am Acad of Orthop Surg. 2021;29(12):527-36. doi: 10.5435/JAAOS-D-20-00122. PMID: 33252549. Exclusion reason: Background only

136. Seppanen SM, Kuuskoski R, Makela KT, et al. Intranasal dexmedetomidine reduces postoperative opioid requirement in patients undergoing total knee arthroplasty under general anesthesia. J Arthroplasty. 2021;36(3):978-85.e1. doi:

10.1016/j.arth.2020.09.032. PMID: 33046329. Exclusion reason: Ineligible intervention

137. Sethi PM, Mandava NK, Liddy N, et al. Narcotic requirements after shoulder arthroplasty are low using a multimodal approach to pain. JSES Int. 2021;5(4):722-8. doi: 10.1016/j.jseint.2021.02.005. PMID: 34223421. Exclusion reason: Ineligible intervention

138. Shah NM, Andriani LA, Mofidi JL, et al. Therapeutic suggestion in postoperative pain control: a randomized controlled trial. Female Pelvic Med Reconstr Surg. 2021;27(7):409-14. doi: 10.1097/SPV.0000000000000906. PMID: 32541300. Exclusion reason: Ineligible intervention

139. Sharma NK, Aoyagi K, Crouch Young MK, et al. Protocol for testing yoga to reduce post-lumbar spine surgery pain: a methodology article. Int J Yoga Therap. 2021 doi: 10.17761/2021-D-20-00016. PMID: 34280297. Exclusion reason: Ineligible publication type/not a study

140. Sharma TH, Vasudeva V, Patil K, et al. An observational study to compare epidural tramadol and epidural fentanyl for postoperative analgesia in lower limb orthopaedic replacement surgeries. Indian J Forensic Med Toxicol. 2021;15(3):557-66. doi: 10.37506/ijfmt.v15i3.15363. Exclusion reason: Ineligible intervention

141. Singh T, Kathuria S, Jain R, et al. Premedication with pregabalin $150 \mathrm{mg}$ versus $300 \mathrm{mg}$ for postoperative pain relief after laparoscopic cholecystectomy. J Anaesthesiol Clin Pharmacol.

2020;36(4):518-23. doi: 10.4103/joacp.JOACP_440_19. PMID: 33840934. Exclusion reason: Ineligible intervention

142. Singh A, Zai CC, Freeman N, et al. Supporting pharmacogenetic-guided opioid prescriptions for post-operative pain: the design, protocol and preliminary results of the OTP Study. J Psychiatr Res.

2021;138:24-33. doi: 10.1016/j.jpsychires.2021.03.040. PMID: 33812277. Exclusion reason: Background only

143. Singla N, Bertoch T, Shenoy S, et al. Efficacy and safety of single-dose DFN-15 for treatment of acute postsurgical dental pain: a randomized, double-blind, placebocontrolled study. Pain. 2021 doi: 10.1097/j.pain.0000000000002312. PMID: 34252915. Exclusion reason: Ineligible 
comparator

144. Sisco-Taylor BL, Magel JS, McFadden M, et al. Changes in pain catastrophizing and fear-avoidance beliefs as mediators of early physical therapy on disability and pain in acute low-back pain: a secondary analysis of a clinical trial. Pain Medicine. 2021;06:06. doi: 10.1093/pm/pnab292. PMID: 34613379. Exclusion reason: Ineligible intervention

145. Smith WR, Ataga KI, Saraf SL, et al. The effect of crizanlizumab on the number of days requiring opioid use for management of pain associated with vaso-occlusive crises in patients with sickle cell disease: results from the sustain trial. Blood. 2020;136(SUPPL 1):32-3. doi: 10.1182/blood-2020-140428. PMID: CN-02271432 NEW. Exclusion reason: Ineligible comparator

146. Soares LO, Ferreira GE, Costa LOP, et al. Meditation for adults with non-specific low back pain: a systematic review and metaanalysis. Scand J Pain. 2021;13:13. doi: 10.1515/sjpain-2021-0096. PMID: 34516731. Exclusion reason: Inadequate duration

147. Solanki SL, Thota RS, Rajan J, et al. Multimodal opioid sparing onco-anesthesia: A consensus practice guideline from Society of Onco-Anesthesia and Perioperative Care (SOAPC). Journal of Opioid Management. 2021;17(5):417-37. doi: https://dx.doi.org/10.5055/jom.2021.0675. PMID: 34714542. Exclusion reason: Background only

148. Stryder BT, Szakiel PM, Kelly M, et al. Reduced opioid use among patients who received liposomal bupivacaine for ACL reconstruction. Orthopedics.

2021;44(2):e229-e35. doi: 10.3928/01477447-20210104-03. PMID: 33416897. Exclusion reason: Ineligible intervention

149. Su X, Qian H, Chen B, et al. Acupuncture for acute low back pain: a systematic review and meta-analysis. Ann Palliat Med. 2021;10(4):3924-36. doi: 10.21037/apm-201998. PMID: 33894708. Exclusion reason: Background only

150. Tamboli M, Mariano ER, Gustafson KE, et al. A multidisciplinary patient-specific opioid prescribing and tapering protocol is associated with a decrease in total opioid dose prescribed for six weeks after total hip arthroplasty. Pain Med. 2020;21(7):1474-81. doi: 10.1093/pm/pnz260. PMID: 31710680.

Exclusion reason: Ineligible outcome

151. Tangtiphaiboontana J, Figoni AM, Luke A, et al. The effects of nonsteroidal antiinflammatory medications after rotator cuff surgery: a randomized, double-blind, placebo-controlled trial. J Shoulder Elbow Surg. 2021;30(9):1990-7. doi: 10.1016/j.jse.2021.05.018. PMID: 34174448. Exclusion reason: Ineligible intervention

152. Tay HP, Wang X, Narayan SW, et al. Persistent postoperative opioid use after total hip or knee arthroplasty: a systematic review and meta-analysis. Am J Health Syst Pharm. 2021;19:19. doi: 10.1093/ajhp/zxab367. PMID: 34537828. Exclusion reason: Inadequate duration

153. Tctr. Intranasal ketamine versus intravenous morphine for older adults with musculoskeletal pain in the emergency department: a randomized controlled trial. http://www.who.int/trialsearch/Trial2.aspx? TrialID=TCTR20201229004. 2020.

Exclusion reason: Ineligible publication type/not a study

154. Theosmy EG, Bradian AK, Cheesman QT, et al. Opioid-free arthroscopic rotator cuff repair. Orthopedics. 2021;44(2):e301-e5. doi: 10.3928/01477447-20201216-03. PMID: 33373466. Exclusion reason: Ineligible study design

155. Tobias AF, Moura EC, Honda CA, et al. Evaluation of the efficacy of prolonged pregabalin administration before and after surgery in patients undergoing arthroscopic anterior cruciate ligament repair: a prospective, randomized, double-blind study. Clin J Pain. 2020;36(8):584-8. doi: 10.1097/AJP.0000000000000841. PMID: 32398443. Exclusion reason: Ineligible intervention

156. Topdemir EA, Saritas S. The effect of acupressure and Reiki application on patient's pain and comfort level after laparoscopic cholecystectomy: a randomized controlled trial. Complement Ther Clin Pract. 2021;43:101385. doi: 10.1016/j.ctcp.2021.101385. PMID: 33836405. Exclusion reason: Ineligible 
population

157. Torabi J, Kaban JM, Lewis E, et al. Ketorolac use for pain management in trauma patients with rib fractures does not increase of acute kidney injury or incidence of bleeding. Am Surg. 2021;87(5):790-5 . doi: 10.1177/0003134820954835. PMID: 33231476. Exclusion reason: Ineligible intervention

158. Tran KK, VanDaele MA, Tran S, et al. Evaluation of acute postoperative pain management during an injectable opioid shortage. Ann Pharmacother.

2021;55(5):611-7. doi:

10.1177/1060028020962037. PMID: 32959671. Exclusion reason: Ineligible comparator

159. Turner NJ, Long DA, Bongiorno JR, et al. Comparing two doses of intramuscular ketorolac for treatment of acute musculoskeletal pain in a military emergency department. Am J Emerg Med. 2021;50:142-7. doi:

10.1016/j.ajem.2021.07.054. PMID: 34365063. Exclusion reason: Ineligible intervention

160. van der Gaag WH, Roelofs DDMP, Enthoven TMW, et al. Non-steroidal antiinflammatory drugs for acute low back pain. Cochrane Database Syst Rev.

2020;4(4):CD013581. doi: 10.1002/14651858.CD013581. PMID: 32297973. Exclusion reason: Background only

161. Vasilopoulos T, Wardhan R, Rashidi P, et al. Patient and procedural determinants of postoperative pain trajectories.

Anesthesiology. 2021;134(3):421-34. doi: 10.1097/ALN.0000000000003681. PMID: 33449996. Exclusion reason: Ineligible intervention

162. Vaughan SA, Torres K, Kaye R. RESUME1: a Phase III study of tolperisone in the treatment of painful, acute muscle spasms of the back. Pain Manag. 2021 doi: 10.2217/pmt-2021-0041. PMID: 34192885. Exclusion reason: Ineligible publication type/not a study

163. Wallen GR, Middleton KR, Kazmi NB, et al. A randomized clinical hypnosis pilot study: improvements in self-reported pain impact in adults with sickle cell disease.
Evid Based Complement Alternat Med. 2021;2021:5539004. doi:

10.1155/2021/5539004. PMID: 34457024.

Exclusion reason: Ineligible population

164. Wang X, Narayan SW, Penm J, et al. Gastrointestinal adverse events in hospitalized patients following orthopedic surgery: tapentadol immediate release versus oxycodone immediate release. Pain Physician. 2021;24(3):E309-E15. PMID: 33988952. Exclusion reason: Ineligible population

165. Wentz AE, Wang RC, Marshall BDL, et al. Opioid analgesics and persistent pain after an acute pain emergency department visit: evidence from a cohort of suspected urolithiasis patients. J Emerg Med.

2021;21:21. doi:

10.1016/j.jemermed.2021.09.002. PMID: 34690022. Exclusion reason: Ineligible outcome

166. Wang J, Zhao G, Song G, et al. The efficacy and safety of local anesthetic techniques for postoperative analgesia after cesarean section: a Bayesian network meta-analysis of randomized controlled trials. J Pain Res. 2021;14:1559-72. doi: 10.2147/JPR.S313972. PMID: 34103981. Exclusion reason: Background only

167. Wilt ZT, Tan TL, Rondon AJ, et al. Preoperative sedative use and other risk factors for continued narcotic use after total knee arthroplasty: a comprehensive analysis of a mandatory database. Orthopedics. 2021;44(1):e50-e4. doi: 10.3928/0147744720201026-01. PMID: 33141227. Exclusion reason: Ineligible intervention

168. Wladis EJ, Rothschild MI, Rubinstein TJ. Management of postoperative pain in ophthalmic plastic surgery: a major review. Orbit. 2021;40(4):269-73. doi: 10.1080/01676830.2020.1793373. PMID: 32669009. Exclusion reason: Ineligible study design

169. Wolf SJ, Byyny R, Carpenter CR, et al. Clinical Policy: Critical Issues Related to Opioids in Adult Patients Presenting to the Emergency Department. Annals of Emergency Medicine. 2020;76(3):e13-e39. doi: 10.1016/j.annemergmed.2020.06.049. Exclusion reason: Background only

170. Wouters RM, Porsius JT, van der Oest 
MJW, et al. Psychological characteristics, female sex, and opioid use predict acute postoperative pain in patients surgically treated for thumb base osteoarthritis: a cohort study. Plast Reconstr Surg. 2020;146(6):1307-16. doi: 10.1097/PRS.0000000000007337. PMID: 33234961. Exclusion reason: Ineligible outcome

171. Wolf SJ, Byyny R, Carpenter CR, et al. Clinical Policy: Critical Issues Related to Opioids in Adult Patients Presenting to the Emergency Department. Annals of Emergency Medicine. 2020;76(3):e13-e39. doi: 10.1016/j.annemergmed.2020.06.049. Exclusion reason: Background only

172. Xuan C, Yan W, Wang D, et al. Effect of preemptive acetaminophen on opioid consumption: a meta-analysis. Pain Physician. 2021;24(2):E153-E60. doi: n/a. PMID: 33740343. Exclusion reason: Background only

173. Yin X, Wang X, He C. Comparative efficacy of therapeutics for traumatic musculoskeletal pain in the emergency setting: a network meta-analysis. Am J Emerg Med. 2021;46:424-9. doi: 10.1016/j.ajem.2020.10.038. PMID: 33131973. Exclusion reason: Inadequate duration

174. Yu R, Zhuo Y, Feng E, et al. The effect of musical interventions in improving shortterm pain outcomes following total knee replacement: a meta-analysis and systematic review. J Orthop Surg Res. 2020;15(1):465. doi: 10.1186/s13018-020-01995-x. PMID: 33036637. Exclusion reason: Inadequate duration

175. Yu XJ, Zhang L, Lu WY, et al. [Effect of electroacupuncture combined with caudal epidural injection on functional rehabilitation of patients with lumbar hernia]. Zhen Ci Yan Jiu. 2021;46(7):605-9. doi: 10.13702/j.1000-0607.200383. PMID: 34369682. Exclusion reason: Study covered in included systematic review

176. Zamora FJ, Madduri RP, Philips AA, et al. Evaluation of the efficacy of liposomal bupivacaine in total joint arthroplasty. $\mathrm{J}$ Pharm Pract. 2021;34(3):403-6. doi: 10.1177/0897190019872577. PMID: 31526058. Exclusion reason: Ineligible intervention

177. Zhang M, Zhang SQ, Ma S, et al. Collateralpricking and blood-letting cupping combined with electroacupuncture for postherpetic neuralgia. World J Acupunct Moxibustion. 2021;31(3):172-5. doi: 10.1016/j.wjam.2021.05.010. Exclusion reason: Ineligible population

178. Zhu CY, Schumm MA, Hu TX, et al. Patient-centered decision-making for postoperative narcotic-free endocrine surgery: a randomized clinical trial. JAMA Surg. 2021:e214287. doi: 10.1001/jamasurg.2021.4287. PMID: 34495283. Exclusion reason: Ineligible outcome

179. Zhu L, Li L, Yin B, et al. Effect of continuous nursing combined with salcatonin on postoperative pains in elderly patients after hip replacement. Am J Transl Res. 2021;13(5):5264-71. PMID: 34150117. Exclusion reason: Ineligible intervention 


\section{Appendix E. Evidence Tables}

Shown in associated Excel files for surveillance report 1 at https://effectivehealthcare.ahrq.gov/products/treatments-acute-pain/research. 


\section{Appendix F. Quality Assessment}

Shown in associated Excel files for surveillance report 1 at https://effectivehealthcare.ahrq.gov/products/treatments-acute-pain/research. 